
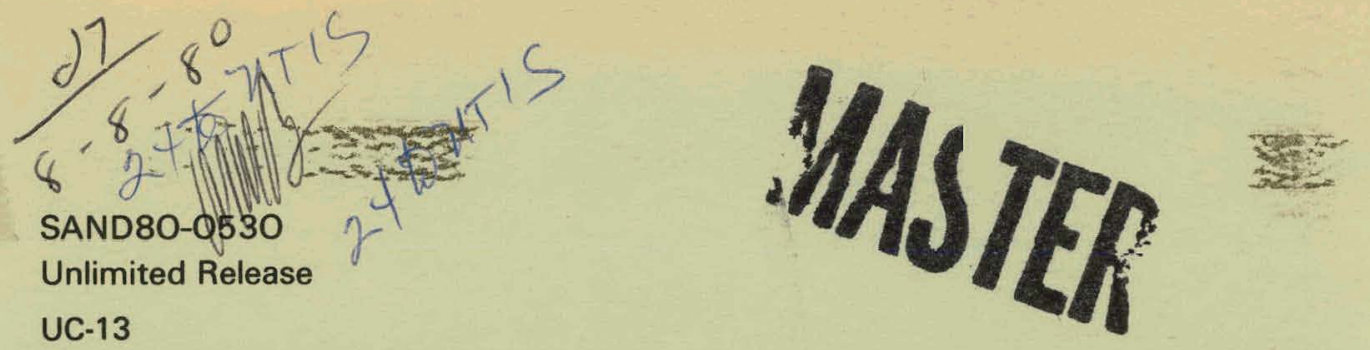

\title{
Who Dunnit?
}

\section{A Crash Course in Style for Sandia Authors}

Larry S. Lopez

Prepared by Sandia Laboratories, Albuquerque, New Mexico 87185 and Livermore, California 94550 for the United States Department of Energy under Contract DE-ACO4-76DPOO789

Printed July 1980

\section{Sandia National Laboratories}




\section{DISCLAIMER}

This report was prepared as an account of work sponsored by an agency of the United States Government. Neither the United States Government nor any agency Thereof, nor any of their employees, makes any warranty, express or implied, or assumes any legal liability or responsibility for the accuracy, completeness, or usefulness of any information, apparatus, product, or process disclosed, or represents that its use would not infringe privately owned rights. Reference herein to any specific commercial product, process, or service by trade name, trademark, manufacturer, or otherwise does not necessarily constitute or imply its endorsement, recommendation, or favoring by the United States Government or any agency thereof. The views and opinions of authors expressed herein do not necessarily state or reflect those of the United States Government or any agency thereof. 


\section{DISCLAIMER}

Portions of this document may be illegible in electronic image products. Images are produced from the best available original document. 
Issued by Sandia National Laboratories, operated for the United States Department of Energy by Sandia Corporation.

NOTICE : This report was prepared as an account of work sponsored by an agency of the United States Government. Neither the United States Government nor any agency thereof, nor any of their employees, nor any of their contractors, subcontractors, or their employees, makes any warranty, express or implied, or assumes any legal liability or responsibility for the accuracy, completeness, or usefulness of any information, apparatus, owned rights. Reference herein to any sents that its use would not infocess, or service by trade name, trademark, manufacturer, or otherwise, does not necessarily constitute or mply its endorsement, recommendation, or favoring by the United States Government, any agency thereof or any of their contractors or subcontractors. The views and opinions expressed herein do not necessarily state or reflect those of the United States Government, any agency thereof or any of their contractors or subcontractors.

Printed in the United States of America

Available from

National Technical Information Service

U. S. Department of Commerce

5285 Port Royal Road

Springfield, VA 22161

NTIS price codes

Printed copy: $\quad \$ 7.00$

Microfiche copy: $A 01$ 


\section{PAGES 1 to 2 WERE INTENTIONALLY LEFT BLANK}


SAND80-0530

Unlimited Release

Printed July 1980
Distribution

Category UC-13

WHO DUNNIT?

A CRASH COURSE IN STYLE FOR SANDIA AUTHORS

Larry S. Lopez

Technical Writing Division 3151

Sandia National Laboratories

Albuquerque, NM $\mathbf{8 7 1 8 5}$
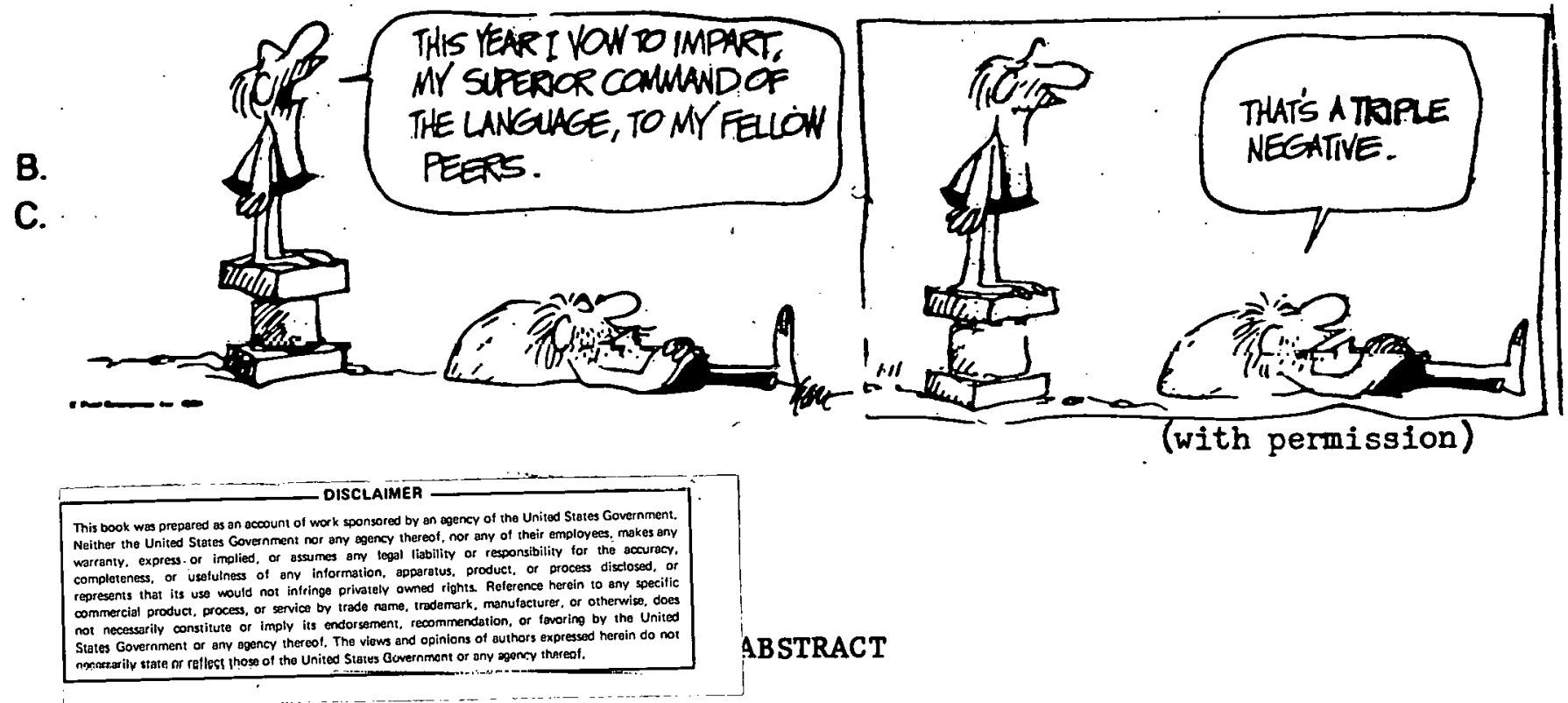

This is a short course for the busy engineerscientist who wants to write reports that meet minimum standards of modern technical writing. The text stresses some cardinal rules of good writing: personal pronouns, strong verbs, active voice, elear exprcsoion, and avoidance of $j$ argon and noun modifiers. 


\section{CONTENTS}

You Be The Judge

Introduction

Who Dunnit?

Verbal Assault

Action!

Caveat on Phenomenological Criteria for Thesauri,

Enchiridia, and Other Compendia 25

$\begin{array}{ll}\text { Jargon } & 29\end{array}$

Extreme Length Noun Modification/Qualification Word Queues 31

Polish 33

Postword (by Supervisor, Division 3151) 37

References 38

Appendix A 39

$\begin{array}{ll}\text { Appendix B } & 49\end{array}$

Appendix C $\quad 55$ 
WHO. DUNNIT?

A CRASH COURSE IN STYLE FOR SANDIA AUTHORS

You Be The Judge

Below are three phrases extracted from the draft of an actual report. Pick the best way of expressing the underlined passage.

The scientist is trying to determine

1. "The mechanism, rate, and directional nature of concrete erosion by the melt."

a. The original version.

b. How, how fast, and in which direction the molten materials erode the concrete.

c. The mechanical process, the speed, and the radial direction involved in the erosion of concrete by the molten material.

d. Concrete erosion by the mèt, by identifying what causes it, how fast it happens, and what shape the resulting cavity assumes.

e. The physical forces, quantitative considerations as a factor of time, and spatial extensions involved in melt/concrete interactions resulting in erosion of the concrete.

2. "The generation rate and nature of evolved noncondensable gases."

a. The original version.

b. The nature of noncondensable gases and how fast they generate.

c. Time factors involved in generating noncondensable gases, the chemical composition of these gases, and the phenomena of their behavior.

d. The rate at which noncondensable gases evolve and their nature. 
e. The behavioral and chemical attributes of noncondensable gases and quantitative versus temporal factors involved in their evolution.

3. "The effects of gas generation on fission product release."

a. The original version.

b. What role these gases play on whether fission products are released or not.

c. How the act of generating gases affects release of fission products.

d. What influence generated gases have on the release or retention of fission products.

e. What effects the generation of gases has on the inevitable release of fission products.

Now, if we all had the time to spend analyzing every sentence in every report in so thorough a manner, the quality of Sandia technical writing would skyrocket. But I'm sure you don't have the time; you barely have the time to perform your own job, much less to write about it. However, if you merely agree that the original version could stand improvement, this is the course for you. 
Introduction

For some twenty years, technical writers have been emphasizing the negative aspects of scientific and engineering writing, endlessly berating the "verbal pollution" that masquerades as serious writing. Then, after .....thoroughly drubbing the object of their contempt -- the hapless engineerscientist -- they are surprised that he does not cheerfully disregard his years of training, fall out of lockstep with his peers, and adopt the standards of another profession: technical writing.

This reminds me of a TV show in which a well-meaning teacher took responsibility for several deprived children who had exhausted the patience of other instructors. In the group was a boy, about 10 years old, who still wet his pants. Countless adults had admonished him. All the children teased him. In a flash of epiphany* she deduced that he simply had never been taught. Improvement was immediate and lasting!

As with all professions, engineer-scientists have their apologists who readily concede the negative aspects of their clients' writing but go to great lengths to justify the reasons for the awful results of melding scientific pursuits with ink. ${ }^{1}$ Some even sound convincing -- until once more we blanch at the results.

Almost unanimously, modern technical writers declare that scientific and engineering writing is the worst on the market. Why, then, can't we do something about it? After all, the end of every scientific endeavor is not the project itself or its results, but a communication. However high a particular discipline may rate its endeavors, however important it may regard its research and results, all -- without exception -- have something in common. That something is REPORTING ITS METHODS AND FINDINGS. Without communication and consequent monitoring by peers there is no science. Communication is at the apex of every endeavor; it is the capstone, the final and most important act of any research project.

\footnotetext{
*The "Aha!" syndrome, a SWAG, euphuistically called "an engineering judgmental delesmiliation" by thoce trying to hestow dignity on an educated guess.
} 
Why, then, does the literature abound with such blatant disregard for clear, understandable writing? Perhaps J. B. Reubens has the answer: ${ }^{2}$

\begin{abstract}
Many engineers and scientists make no attempt to write well because there is no incentive to do so. This lack of incentive is chargeable to the failure of journal editors, chairmen of technical programs, and "in-house" readers to insist on good writing. Editors hesitate to edit, fearing that cutting or revision may affect accuracy adversely. This, in spite of expert consultants, scientist-editors, telephones to reach authors, and tape to record agreement on any proposed chainges. "In-house" readers, members of the same organization as the writcr of a papes, lend to be over-scrupulous of a colleague's feelings or hesitate to comment because they fear retribution when one of their own papers comes up for reading.

To correct bad writing is regarded as an insult to the author instead of an important service. Summarized, the general attitude is: If the substance is correct, who cares how the paper is written? Given this general acceptance of inferior writing, there is little incentive to learn to write well. And, by a sort of Gersham's law, bad writing drives out good. No wonder that so much bad scientific writing appears.
\end{abstract}

Reubens, of course, is right on the mark. However, he is describing symptoms, the outward manifestation of something deeper, a latent hostility toward accepting help. H. J. Tichy describes this inherent sensitivity: ${ }^{3}$
A man's feelings about his writing are more sensitive and tender than his feeling about his performance in his science or technology . . . he takes criticism as a reflection of his inner self. An engineer will defend at length a dangling modifier or pronoun without an antecedent but he will correct an error in engineering the moment it is pointed out to him . . . such people argue interminably about insignificant details....

Okay, let us assume that the engineer-scientist, being mature, concedes the point. He agrees that his material could stand improvement. "But," he laments, "I haven't the time or energy to take an in-depth writing course. Anyway, by the time it is over, I will have forgotten half the stuff. What is parallelism? What is the passive voice? What, pray tell, are antecedents, split infinitives? Aarargh!" 
Although he is hedging, there is some truth to what he says. I think that we need a crash course on style. Leave the mechanics for an editor. And the author should be able to refer quickly to his textbook to refresh $h$ is memory and refine $h$ is techniques.

Before we get started, let's get the troublesome grammar out of the way:

\section{The Ten Commandments of Good Writing ${ }^{4}$}

1) Each pronoun should agree with their antecedent.

2) Just between you and $I$, case is important.

3) A preposition is a poor word to end a sentence with.

4) Verbs has to agree with their subjects.

5) Don't use no double negatives.

6) A writer mustn't shift your point of view.

7) When dangling, don't use participles.

8) Join clauses good, like a conjunction should.

9) Don't write a run-on sentence because it is difficult when you got to punctuate it so it makes sense when the reader reads what you wrote.

10) About sentence fragments.

I will add another two:

11) To frequently split infinitives is bad writing.

12) Avoid redundant pleonasms.

Now that we are experts on all the essential gramar we need, let us move on to style. All modern technical writers agree on the following positive aspects:

- Do use personal pronouns

- Do use verbs to carry the action

- Do use the active voice as much as possible

- Do use simple and unadorned rather than flowery and baroque English

- Do avoid jargon

- Do avoid long choo-choo trains of noun modifiere 
That's all! Once we decide to go the direct route of the professionals we are surprised how quickly and easily our writing improves. And, with clear writing comes clear thinking.

One more thing. Applying these guidelines does not guarantee you a style of your own; it does not guarantee you polish. There are only three ways to acquire polish: practice, practice, practice.

The best way to practice and eventually develop your own style is imitation. Yes, imitation! Choose a writer whose clarity and intellect you admire. Then make a conscious and sustained effort to imitate him.Imitation is not slavish. All great technical writers, from Aristotle to Benjamin Franklin, ${ }^{5}$ from Kepler to Asimov, have imitated those they admired. In the end, your own style emerges, forever identifying you as personally as do your fingerprints.

I cannot blame the engineer-scientist for being impatient with longwinded dissertations, so this text is purposely brief. For practice material I have picked part of a single report as a typical document that could stand considerable improvement. Some reports are worse; some are better; but the authors typify average scientific authors with their habits of expression and their use of all that should be avoided.

I have included some articles on technical writing-in the Appendixes. They are not vital to the subject but they may be of interest, especially to professional writers. 
Who Dunnit?

The opening paragraph -- indeed, the entire text -- of this typical publication leaves me searching vainly for "who dunnit?" Can you guess?

The Molten Core/Concrete Interactions Study was begun on July 15, 1975, to provide a qualitative, extensive exploration of the phenomena associated with contact between molten-core materials and concrete. The experimental elements of this study are divided into four categories:

1. Deposition of Corium-type melts onto concrete.

2. Kinetics and stoichiometry of the thermal decomposition of concrete.

3. Response of concrete to high heat fluxes at one surface.

4. Simulation experiments which explore phenomena at the interface between a melt and a decomposing solid.

Why are engineers and scientists afraid of the personal pronoun? Are they
$\square$ Timid?
Diplomat ic?
Considerate?
Modest?
Shrewd?
All of the above?
Objective?
Careful?

Let us assume that you wrote the above paragraph. Now, go ahead! Force yourself into the picture. Accept responsibility and credit for what you do. If the plunge into the personal pronoun $I$ is too icy and makes you shiver, stick a toe in first by using the collective we (see the Postword). Type the paragraph on scrap paper, triple space. Blot out unwanted words and letters with correction tape and write in substitute words with erasable pencil. Shift phrases around if necessary. Now compare it with the massaged version below:

The Molten Core/Concrete Interactions Study we began on July 15, 1975, to provide a qualitative, extensive exploration of the phenomena associated with contact 


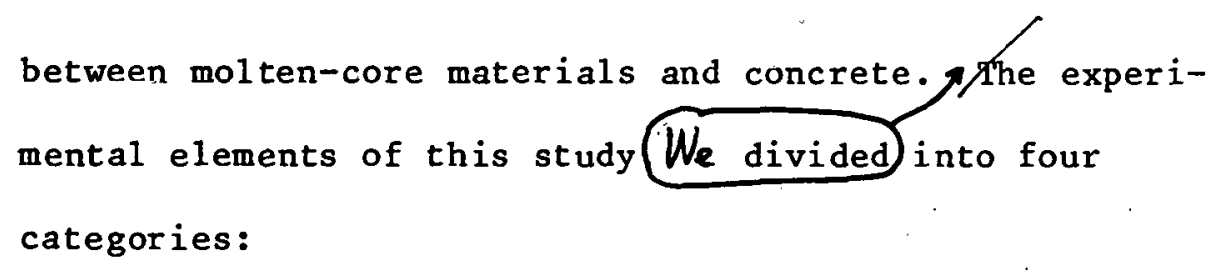

1. Deposition of Corium-type melts onto concrete.

2. Kinetics and stoichiometry of the thermal decomposition of concrete.

3. Response of concrete to high heat fluxes at one surface.

4. Simulation experiments which explore phenomena at. the interface between a melt and a decomposing solid.

Notice that this simple modification rayses two otartling and desilable effects almost automatically. We interject human beings into an otherwise dreary landscape and we transform passivity into action, two techniques that all modern technical writers endorse.

Let us try another passage:

Programing activities included the writing, coding, and checkout of a primitive CORCON main or driver program containing mostly dumy subroutines. In addition, several. phenmenological modcl and data handling oubroutines were completed, incorporated into CORCON, and checked out.

Retype the passage, take out your correction tape, and insert the personal pronoun wherever you can: 


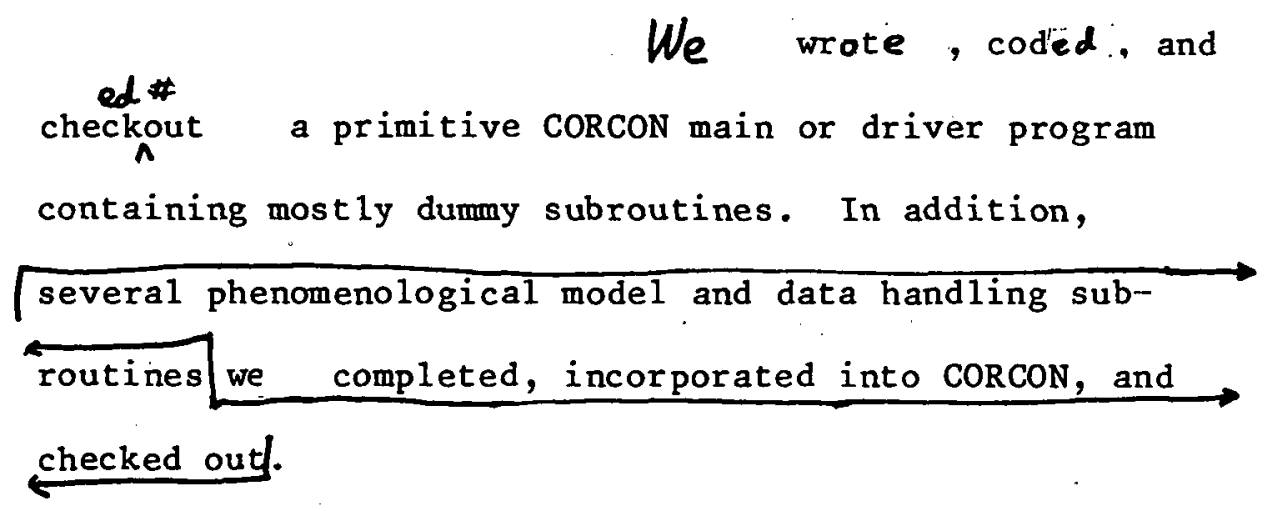

Notice again how easily we slid into the active voice once we decided to personalize and take responsibility for what we did. There is another benefit in the first sentence: we transform those noun-like gerunds into the real verbs they are trying to imitate. We also get rid of some redundancy (programing... program).

Let's try another passage:

Even though both bridgewire and detonator stimulation were used and also a variety of time delays between flooding and attempted initiation (Table 2-1), it was not possible to initiate an interaction in the arcmelting apparatus which could be regarded as a typical steam explosion. It was possible, however, to drive the melt into unusual configurations. . .

Even though both bridgewire and detonator we stimulated the molt with used and also $a$ variety of time delays between flooding and attempted initiation (Table 2-1), whe could not initiate an interaction in the arcmelting apparatus which ${ }_{\wedge}$ could. regard as a typical steam explosion. We were able, however, to drive the melt into unusual configurations. . . 
By using the personal pronoun, we were forced -- however much we wanted to hedge -- to identify for the reader what was being stimulated and how. At the same time we avoided the clumsy construction linking the first and second clauses in the opening sentence ("and also a variety"). By taking responsibility for and admitting our inability to start an explosion, we did away with the rather dubious "it was not possible." Perhaps it is; who knows? Just because we can't do it signifies nothing. Then, in the last sentence, look at the joy of discovering that we could, after a11, do something! We also eliminated an ambiguity: "the arc-melting apparatus which could be regarded as a typical steam explosion."

One more passage and $1^{\prime} 11$ turn you loose:

The major reason why steam explosions are of interest in hypothetical core melt accidents is that they can provide a separate mechanistic path for radiological transport into the containment and possible containment failure. Therefore, the final portion of this research work is to couple the experimentally; observed and expected steam explosion efficiencies with an analysis of the containment failure capability. . .

The major reason why steam explosions during interest us hypothetical core melt accidents ${ }_{\text {is }}$ that they can provide a separate mechanistic path for radiological transport into the containment and possible containment

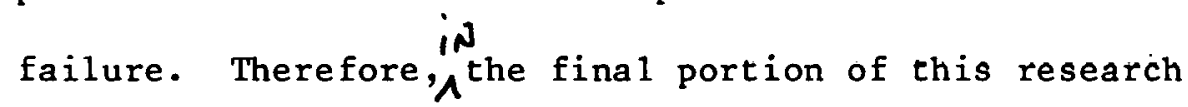
work, we will couple the experimentally observed and expected steam explosion efficiencies with an analysis of the containment failure capability. . . 


\section{Verbal Assault}

Verbs are draft horses; nouns are lap dogs. Verbs are designed to carry the action; they are the engine, the power, the energy propelling the sentence forward, giving it punch, oomph. To make a noun perform the verb's duty is to emasculate the language. It does a disservice to the noun (the poor thing is in over its head) and forces the sentence into a state of passivity.

Let's go back to the first partially reconstructed paragraph:

On July 15, 1975 we began the Molten Core/Concrete Interactions Study to provide a qualitative, extensive exploration of the phenomena associated with contact between molten-core materials and concrete. We divided the experimental elements of this study into four categories:

1. Deposition of Corium-type melts onto concrete.

2. Kinetics and stoichiometry of the thermal decomposition of concrete.

3. Response of concrete to high heat fluxes at one surface.

4. Simulation experiments which explore phenomena at the interface between a melt and a decomposing solid.

Look for those nouns masquerading as verbs and identify their verb counterparts: exploration = explore; deposition = deposit; response = respond; simulation = simulate. Now, let us tackle the passage with correction tape and pencil:

On July 15, 1975 we began the Mol.ten Core/Concrete

Interactions Study to

qualities of

explore. the ${ }_{\wedge}$ phenomena associated with contact

between molten-core materials and concrete. We divided 
the experimental elements of this study into four

Tasks:

1. Depositing Corium-type melts onto concrete.

Studying the

2. AXinetics and stoichiometry of the thermal decomposition of concrete.

Determiniag how

3. Responds nconcrete to high heat fluxes at one surface.
4. Simulating The
phenomena at
the interface between a melt and a decomposing solid.

Notice that almost immediately we are forced to explain what we mean by "qualitative." We also discover that the four categories are not really categories but tasks (the context later clarifies that the study is divided into two portions: experiments and modeling). The use of the verbs reveals at once that the four tasks are not grammatically parallel; because No. 2 does not even seem to be related to the others, we are forced to bring it into the family. Notice that in No. 4 we have to explain what we are simulating and consequently can do away with superfluous material: "experiments which explore." (At the very beginning we stated that the experiments were divided into four tasks and that the purpose of the study was to $\exp 1$ ore.)

Let's go to the next passage:

We wrote, coded, and checked out a primitive CORCON main or driver program containing mostly dumm subroutines. In addition, we completed, incorporated into CORCON and checked out several phenomenological model and data handling subroutines. 
We find that merely by using the personal pronoun we had already performed most of our task. Let's try another.

Even though we stimulated the melt with both bridgewire and detonator and used a variety of time delays between flooding and attempted initiation (Table 2-1), we could not initiate an interaction in the arc-melting apparatus which we could regard as a typical steam explosion. We were able, however, to drive the melt into unusual configurations...

Almost every time you see a noun ending in tion, you can safely assume that it is trying to carry the action: initiation, interaction, etc. Although we have already transformed some nouns into verbs when we used the personal, let's tackle these and their cohorts (flooding, delays, etc.).

This exercise forces us to question the meaning of our words. What was flooded? What did we attempt to initiate? What are "time delays?" Are there any other kind?. What kind of interactions are we unable to initiate? What things are interacting? How?

The context shows that as pellets are melted in the arc hearth the molten material is suddenly inundated with water. The scientist working on the project then activates a submerged bridgewire or detonator, sending a shockwave through the water. This shockwave is supposed to force the hot molten material to interact with the water, turning the water into steam. The sudden expansion creates a so-called steam explosion. During the experiment, the trigger, whether detonator or bridgewire, is activated at varying times after the hearth is flooded.

Once we have determined this sequence, we can use verbs to get rid*of a lul of superfluous -- realiy meaningless -- words. However, notice that we must do some drastic rewriting:

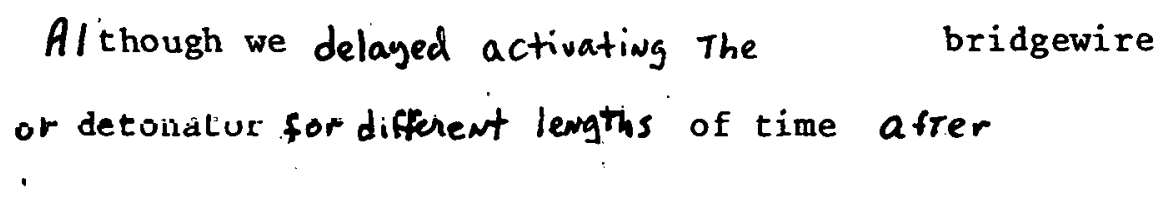




\section{Was flooded (Table 2-1), we could not force the water to $n$ interact in the arc-melting apparatus with the melt and cause a typical steam explosion. The Shock- wave , however, did drive the melt into unusual con- figurations . . .}

Such is the power of verbs! Let's go on to the next passage:

The major reason why steam explosions during hypothetical core melt accidents interest us is that they can provide a separate mechanistic path for radiological transport into the containment and possible containment failure. Therefore, in the final portion of this research work, we will couple the experimentally observed and expected steam explosion efficiencies with an analysis of the containment failure capability. . .

Here we have a problem: what's the passage trying to say? We can correct all the nouns that seem to be carrying the action (transport, failure, analysis, capability, perhaps even containment) yet the paragraph still sounds unclear. The guilt lies in the verb "provide." Whenever a writer uses this verb, you can almost bet he is trying to sneak in some nouns to weaken che action. What is pruvided? A path and failure. Doco a steam explosion provide? No! An explosion causes things to happen, dramatically and vigorously. Why not say so?

Two major reasons why steam explosions during hypothetical core melt accidents interest us is that (1) they can rupture the reactor vessel, a llowing fission products to enter the containment structure and (2) They may cause The structure itself to fail. Therefore, in the final portion of this research work, we will combine the experimentaily observed and expected steam explosion efficiencies with an analysis of the containment's. 
While groping for something to replace "provide" we discover that "separate mechanistic path" is eyewash for a crack in the reactor vessel or piping. "Radiological transport" turns out to be a movement of fission products, and "containment" is merely the building that houses the reactor. We also find that just because fission products leak into the building does not automatically cause it to weaken or otherwise fail. Therefore, there are really two reasons that steam explosions interest us.

In the second paragraph, we are coupling "efficiencies" with "analysis." At this juncture we cannot change "efficiencies" into a verb, and since we must maintain parallelism (we cannot couple a noun to a verb), let us skip this wording for the moment and go to a "failure capability." Does the containment building have the capability to fail? This is a rather disturbing discovery of something actually built into the structure, something on the order of self-destruction. Are we analyzing its susceptibility to failure or are we analyzing the steam explosion's capability to cause it to fail? Context reveals that we will be analyzing the strengths and weaknesses of the building itself. The word "couple" is a rather dubious choice; we are victims of our monogamous social environment and we tend to think of coupling as the joining of two entities. Here we have two types of efficiencies being coupled.to one analysis. To avoid raised eyebrows, it is wise to use "combine."

Although the paragraph is improved, we still have a lot of work to do on it bcfore our readers can determine what we mean. 


\section{Action!}

The whole cosmos is in eternal motion: electrons whirl around their nuclei, planets revolve around their suns, galaxies hurtle away from each other. For Man, the fundamental need is activity; pasșivity soon kills him.

Our 1 anguages reflect this eternal restlessness. Nobody speaks naturally in the passive voice (my nose was struck by his fist). The passive is a contrived, artificial aberration of the 1 anguage, mostly confined to written styles. It is one step above the little white lie, invented for the timid who fear responsibility, who are natural hedgers, who are afraid to be pinned down.

To use the active voice is to strike at the heart of the subject; to declare without reservation what the action is, who is doing what to whom. The active voice saves words, it saves guessing, it saves convoluted thinking and writing. It shows guts!

We should use the passive voice sparingly, like spices in cooking, to give a decided, controlled flavor and variety to our writing. Too much active voice, although not noticeable in conversation, tends to give writing a staccato, hysterical nature, like using too many exclamation marks. Every so often, at the appropriate moment, we should throw in some passive voice to slow the pace, add tranquility and a breathing spell to our action-packed manuscript. This use is especially valid when the object receiving the action is more important than the subject.

Notice that in the preceding four paragraphs I used the passive voice only twice, almost disguised as active (confined and invented). All writing -- creative or expository, technical or informal -- is equally adaptable to the active voice; after all, it is English and English is a dynamic language. Let's try it on our selected paragraphs.

After thoroughly inspecting all these paragraphs, we find that by using personal pronouns and verbs, we have only one fragment of passive 
voice left, in the third paragraph: "after the arc-melting apparatus was flooded." We can leave this as it is to add balance to the paragraph, or we can change it to the active "after we had flooded the arc-melting apparatus." 


\title{
Caveat on Phenomenological Criteria for Thesauri, Enchiridia, and Other Compendia
}

\begin{abstract}
"Beware of Greeks bearing gifts" has long been a warning not to take everything at face value, a warning tragically ignored by the Trojans. Be ever suspicious of Latin or Greek brought into English unchanged. Our language is Germanic; when southern immigrants are invited in, both host and guest are uncomfortable. Invariably we get careless and embarrass ourselves. It is best to leave Greek and Latin to the little old professors who prefer sesquipedalia to perspicuity.
\end{abstract}

How can anyone justify "utilize" when we have the perfectly good word "use?" "Via" is almost always misused. In hundreds of reports, I have seen "due to" used correctly only twice. "Viable" has never been used correctly. Why must we use "impact" when we mean "strike," "interface" when we mean "contact," "prior to" when we mean "before," "initiate" when we mean "start?"

Let us review our paragraphs and trim off the fat:

On July 15, 1975 we began the Molten Core/Concrete Interactions Study to explore the qualities of phenomena associated with contact between molten-core materials and concrete. We divided the experimental elements of this study into four tasks:

1. Depositing Corium-type melts onto concrete.

2. Studying the kinetics and stoichiometry of the thermal decomposition of concrete.

3. Determining how concrete responds to high heat fluxes at one surface.

4. Simulating the phenomena at the interface between a melt and a decomposing solid. 
First of all, there is nothing we can do with the name of the study; somebody else in the sacred past invented it and engraved it in stone. Let's skip the "Interaction" in it and proceed to the next suspicious word, "phenomena." One of its many meanings is "a fact or event of scientific interest susceptible of scientific description and explanation." In other words, "Wha hoppen?" Other words susceptible to multiple readings or technically difficult for some administrators are "kinetics, stoichiometry, therma1, fluxes, and interface."

On July 15, 1975 we began the Molten Core/Concrete Interactions Study to explore Contact between molten-core materials concrete. We divided the experimental elements of this study into four tasks:

1. Depositing Corium-type melts onto concrete:

2. Studying the mechaw sens and results os Chamical reactions Taking Place when heat

$A$ decomposes concrete.

3. Determining how concrete responds whenh high heat is applied to of irs oply one surfaces.

4. Simulating a meltdown To study what happens where the melt imeets 1 adecomposing concrite 0

You see, we do not need fancy words to explain complex scientific endeavors! Simply because fancy words exist is no reason to use them if a perfectly good common English word will do. Notice that a good many of the original words are vague enough to send us to a technical dictionary or 
encyclopedia to ferret out their meaning. Such vagueness, while educational for us, is a disservice to some readers who may have important budgetary roles to play.

On to the next passage:

We wrote, coded, and checked out a primitive CORCON main or driver program containing mostly dummy subroutines. In addition, we completed, incorporated into CORCON and checked out several phenomenological model and data handling subroutines.

With the probable exception of "data," I can find only one offensive word: "phenomenological." What could it mean? The text reveals that CORCON is a computer program that models "phenomena." Thus:

We wrote, coded, and checked out a primitive CORCON main or driver program containing mostly dummy subroutines. In addition, we completed, incorporated into CORCON and checked out severalif for data $\rightarrow$ handling subroutines and for modelling eventso

To rid ourselves of foreign baggage, we have to correct another bugaboo of technical writing: the long, sometimes mind-boggling list of modifiers preceding a noun. For instance, "phenomenological model and data handling" modified "subroutines." It is best to break it up into bitesized pieces even if we have to use more words.

The next paragraph has but one bothersome word: "configuration." The word "shape" is not only simpler but more descriptive. The last paragraph is more subtle. "Hypothetical" is a perfectly good word -- if used correctly. In this context, however, it is highly imprecise.

A reactor meltdown has never happened -- in the free world. The so-called China Syndrome remains a politically sensitive figment of the imagination, the unicorn of the modern world: perhaps it can happen, perhapa not. It sounds reasonable enough to be used by prophets of doom to scare us; but until it actually happens, we cannot be sure. 
Since we can't go around causing reactors to fail to see what happens, we are forced to hypothesize. What would happen if the core melted and the molten materials came into contact with the concrete base of the reactor? What would happen if the molten material was suddenly plunged into the liquid that is used to cool the reactor rods under normal conditions?

In other words, because a "hypothetical" core melt accident does not actually exist, it cannot cause steam explosions, rupture. non-existent lines and boilers, non-existent containment buildings. Are we also to be relieved that these dreadful things can happen only during accidents? Do we not have to take into account deliberate acts such as sabotage?

Let's rework our controversial passage to say what we mean:

$$
\text { If steam explosions during }
$$

core meltdown, Perhaps they woold rup-

ture the reactor vessel, allowing fission products to

enter the containment structure and permeps they could cause the

structure itself to fail. Therefore, in the final por-

tion of this research work, we will combine the experimen-

tally observed and expected steam explosion efficiencies

with an analysis of the containment's weaknesses....

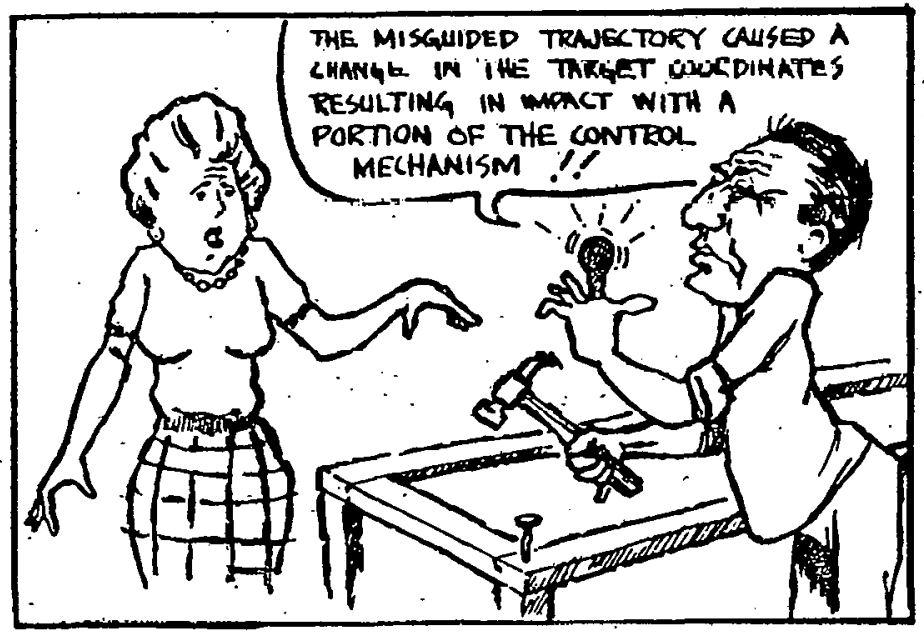

Use simple, direct language to report your information. 
In exchange for freedom of inquiry, scientists are obliged to explain their work. If science is considered a closed priesthood, too difficult and arcane for the average person to understand, the dangers of abuse are great . . .

Carl Sagan

Jargon is 1 anguage peculiar to a particular profession. What argot does for the criminal, jargon does for the scientist: gives him an "in" feeling. I am one of the boys, we speak each other's 1 anguage; it gives us a warm, superior feeling of exclusion when outsiders cannot "dig" what we are discussing. Jargon, from the outsider's point of view, is rude -- if not boorish -- and, in his opinion, belittles the person who uses it. Its use is inexcusable in writing unless it is explained.

Let us see if we can find some in our passages. I can find only one true example of $\mathrm{jargon}$ (Corium) and one that comes close to being jargon (melt). This shortage of jargon in highly unusual, but notice how casually "Corium" is thrown in there, as if the whole world is deficient in not knowing what it means. Such flippancy is characteristic of jargon.

However, there is no dictionary or encyclopedia on the market that contains the word. Out of common courtesy to the reader; it should be explained, preferably in a footnote so as not to distract those readers who al ready know its meaning:

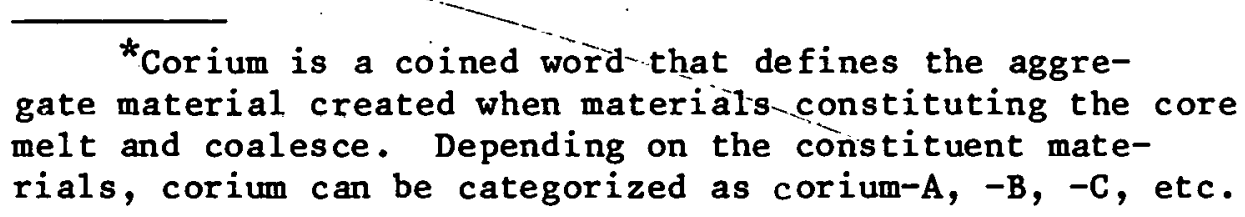

Incidentally the author, almost by reflex, capitalized corium, the . better to give it dignity. Grammatically, there is no more reason to capitalize it than to capitalize tritium, tantalum, or niobium.

The word "melt" to describe the action of melting, the incident, and the result tends to be confusing. Better to use melt, mclt-down, and molten material. 
Extreme Length Noun Modification/Qualification Word Queues

Scientists have a disquieting trait: they use long strings of nouns and adjectives to modify. or qualify another noun. Sometimes it is extremely difficult to distinguish the modifier from the modified. Except for one set, however, most of the noun modifiers remaining in the rewritten passages are within the intellectual (and emotiona1) grasp of the average reader. We find that one in the last paragraph:

Therefore, in the final portion of this research work, we will combine the experimentally observed and expected steam explosion efficiencies with an analysis of the containment's weaknesses.

Can you, at a glance, explain the underlined clause? First we determine that the modified noun is "efficiencies." Efficiency sometimes means the energy-to-work conversion ratio, that is, how much of the energy of the explosion is converted to mechanical work. Now, during the experiment, the scientists observed how much heat was converted to work. With this information they hoped to predict how much work the molten core would produce when dropped suddenly into its cooling liquid. They then would analyze the strengths and weaknesses of the building that contains the reactor and combine the results of this analysis with what they learned of energy conversion. Thus, we have:

- . Through experiments we hope to determine how much heat is converted to work and be able to predict heat-to-work ratios during an actual meltdown. We will then analyze the weaknesses and strengths of the containment building. Finally, culminating our study, we will use our predictions and the conclusions from our analysis of the building to determine if a steam explosion would generate and convert to work enough energy to cause the building to fail in its purpose of containing dangerous fisgion products.

A little bit longer but much-more clarifying. 


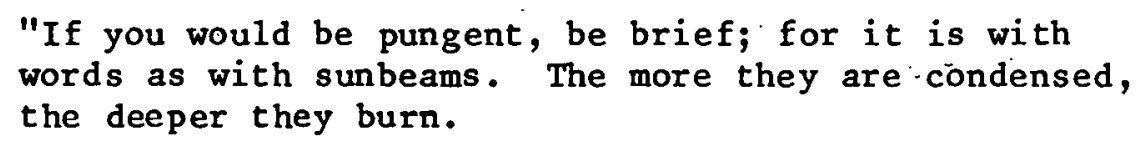
-Robert Southey in
Reader's Digest

To illustrate polish in writing, I like to use a device that resembles an opaque, flattened brandy glass. When I place a small object inside, its mirage floats in mid-air above the device, projected there by an ingenius mirror that itself remains unseen.

So it is with writing. Meaning should float somewhere above the written words. Meaning is the projection of combined words, sentences, punctuation -- even attitudes. The reader should not even notice the words. For example, it takes wood, nails, varnish, and polish to construct a firm, attractive table. Yet, when we look at the table, we are seldom consciously aware of its individual components. If the reader has to pause and puzzle, however slightly, over a word or a group of words, your craftsmanship is faulty.

And remember, the personality of the technical writer is not important; the subject is. To try to impress your reader with. your knowledge of fancy words, your command of Greek or Latin terms, your ability to manipulate English into bizarre shapes is disconcerting. In his admiration for your ability, he may well lose the message. Even worse, he might brand you as an egotistical bore, trying to draw attention to yourself.

Try this. Inspect some of your own writing. Inspect every scholarly word, every word you would not ordinarily use in ordinary conversation with an average literate 1 ayman when trying to explain the same subject. Ask yourself honestly if you unconsciously inserted it to impress your reader. Now, replace it with an ordinary, everyday word. 
Learn to write simple declaratory sentences. Then work on improving your punctuation. What nails and pegs are to furniture, punctuation marks are to writing.

The reconstructed passages need considerable polishing although they are understandable in their present form. For instance, in the first passage, I would move the hyphen in "molten-core materials" to "molten corematerials." Why? The first version means materials from the molten core and are not necessarily still molten themselves. The second version means materials from the core that are in a molten state. Also, I would not use "Corium-type," and I would try to reword "experimental elements," because it is too vague. In the second passage I would somehow explain the terms "primitive CORCON main or driver program." "Primitive" in which respect? Do "main" and "driver" mean the same thing, or are they two different types of programs?

I will let you polish the passages yourself. Also, I will provide you with one final paragraph to sharpen your skills. Remember, use the personal pronoun, no matter how much against your experience it goes. Use verbs to carry the action; nouns weaken the prose. Endeavor to use the active at least $90 \%$ of the time. Flowery, baroque, and Latinized English does not improve style. Jargon is inconsiderate, and Iong strings of modifiers tend to confuse the reader. Here is the paragraph, cleaned of extraneous distractions:

The open geometry tests as reported... indicate that the steam explosions at an intermediate scale have a thermal energy to mechanical work conversion ratio of around $1 \%$. At the present time, there is no way of extrapolating these results to the hypothetical fullscale reactor accident because no scaling experiments at larger scales have been undertaken nor phenomenological models developed to indicate the effect of scale. However, if the intermediate and full-scale conversion 
ratios are assumed to be about the same, then the energy released could be quite large. This energy release will most probably be in the form of local shock waves and acceleration of the water coolant in the lower plenum as a slug, impacting the reactor vessel head. This impact could simply breach the reactor vessel, allowing a release of some of the core inventory, or could also generate a missile by failure of a part or the whole head. WASH-1400 considered that a steam explosion would fail the whole reactor vessel head below the head flange by a brittle failure mechanism. This was considered a conservative failure mechanism in that no credit was given to plastic deformation. has suggested that a steam explosion with a conversion ratio as high as $3 \%$ could not fail the reactor vessel if the failure occurs at the head bolts by a purely ductile failure. This should be recognized as a highly optimistic analysis. These two simple analyses could be looked upon as the bounds to the problem of coupling the impulse of water slug impact to the breaching of the reactor vessel and/or generation of missiles. More mechanistic analysis is being planned to narrow the bounds on this issue to a more realistic spectrum of alternatives... The potential for containment damage if a steam explosion occurs in the reactor cavity will also be evaluated. The conclusion of WASH-1400 was that this scenario for a steam explosion would not lead to containment failure. 
POSTWORD

Some supervisors, either from training or pressures from higher up, demand the third person viewpoint as being more "objective" and desirable for formal reports. Until they are educated otherwise, you may be forced to comply with their attitudes. A little more thought is required, but you can use the third person in the passages you have converted into first person plural and still make use of the active voice. Below are some samples:

The Molten/Core Concrete Interactions Study began on July 15, 1975 to provide a qualitative, extensive exploration of the phenomena associated with contact between molten-core materials and concrete. Studies include four categories of experimental e̊lements: (etc.)

Programmers wrote, coded, and checked out a primitive CORCON main driver program containing mostly dummy subroutines. In addition, they completed, incorporated into CORCON, and checked out several phenomenological models and data handling subroutines.

Neither bridgewire and detonator stimulation nor delays introduced between flooding and attempted initiation (Table 2-1) caused an interaction in the arc melting apparatus which could be regarded as a typical steam explosion. However, these test techniques drove the melt into unusual configurations ... .

W. Lee Garner

Supervisor, Division 3151 
${ }^{1}$ For example, George E. Schindler, Jr., "Why Engineers and Scientists Write as They Do -- Twelve Characteristics of Their Prose," IEEE Transactions on Professional Communications PC-18(2):65 (June 1975).

2John B. Reubens, "Challenge: Good Scientific Writing," IEEE Transactions on Engineering Writing and Speech, EWS-3(2):48-55 (Dec 1965). See Appendix A.

${ }^{3} \mathrm{H}$. J. Tichy, Effective Writing for Engineers, Managers, Scientists (New York: John Wiley \& Sons, Inc, 1966), p 309.

4Robert A. Day, "How to Write a Scientific Paper," IEEE Transactions on Professional Communications (June 1977).

${ }^{5}$ John A. Brogan, "Lessons trom Benjamin Franklin, America's First Great Technical Writer," IEEE Transactions on Engineering Writing and Speech (Jan 1965), pp 3-7. 
APPENDIX A

"Challenge: Good Scientific Writing" (Copyright 1965 by Institute of Electrical and Electronics Engineers, Inc. Reprinted with permission from IEEE Transactions on Engineering Writing and Speech, December 1965, Vol. EWS-8, No. 2, . pp 48+.) 


\title{
Challenge: Good Scientific Writing
}

\author{
JOHN B. REUBENS
}

\begin{abstract}
This article examines three major causes of bad scientific and engineering writing: 1) lack of incentive, 2) lack of interest, and 3) faulty or artificial style. Suggested remedies for each are considered, and a "model" for a paper or report is proposed. Discussion includes brief treatments of the contents of each part of the model, the interrelationships between parts, use of illustrations, and importance of the "communications situation" to style and language level.
\end{abstract}

\section{INTRODUCTION}

Every scientist and engineer pays at least lip scrvice to the importance of keeping up with the literature in his field. Many of them actually try, but even the dedicated few are beginning to wonder if the game is worth the candle. Why? Because, apart from sheer volume, the attempt becomes a struggle when so few "formal publications" are readable; in fact, a well-written one is a rarity. This is appalling when we consider the high average educational level of scientists and engineers and the apparently close connection between intelligence and verbal ability.

Some scientific writing (the term includes engineering writing) is so bad that it is hard to believe the authors completed high school, let alone graduate study at well-known universities. Repeatedly, alleged experts have claimed that bad scientific writing prevails because those in science and engineering, as opposed to the humanities, cannot learn to write well. This is patently false. Anyone who can handle advanced mathematical disciplines certainly has the capacity to learn how to write.

Let us consider some of the principal reasons for the present low "state of the art."

\section{LACK OF INCENTIVE}

Many engineers and scientists make no attempt to write well becausc there is no incentive to do so. This lack of incentive is chargeable to the failure of journal editors, chairmen of technical programs, and "in-house" readers to insist on good writing. Editors hesitate to edit, fearing that cutting or revision may affect accuracy adversely. This, in spite of expert consultants, scientist-editors, telephones to reach authors, and tape to record agreement on any proposed changes. "In-house" readers, members of the same organization as the writer of a paper, tend to be overscrupulous of a colleague's feelings or hesitate to comment because they fear retribution when one of their own papers comes up for reading.

Manuscript received July 24, 1965.

The author is Managing Editor of Central States Construction Magazine, Topek:a, Kan.
To correct bad writing is regarded as an insult to the author instead of an important service. Summarized, the general attitude is: if the substance is correct, who cares how the paper is written? Given this general acceptance of inferior writing, there is little incentive to learn to write well. And, by a sort of Gresham's Law, bad writing drives out good. No wonder that so much bad scientific writing appears.

\section{LACK OF INTEREST IN WRITING WELL}

While editorial failure contributes greatly to the generally poor quality of scientific writing, the ivriters of scientific papers are equally, if not more, to blame for their neglect of communication skills.

What seems to escape scientists and engineers (and a goodly number of writers in the humanities) is that written or spoken language is the only means we have of communicating our thoughts. Gesture, pantomime, and actual physical handling will serve to convey elementary directions and simple emotions. But, without words, we are largely powerless to express our thoughts. Jndeed, there are those who think that thought itself depends on words, "verbal symbols," and on the interrelationship of thesc symbols; no word, no thought.

Whether this school of psychology is correct or not, to convey sophisticated thought, we certainly nced words, and all scientific information is the result of highly sophisticated thought. Why, then, do we find widespread indifference to acquiring communication skill? Or, outright contempt?

The cause is psychological: lack of interest. The reasons for this lack of interest are failure to provide knowledge of English, as a subject, and deliberate inculcation of faulty or artificial style.

Failure to provide a knowledge of English lies at the root of most bad writing, scientific or other. Unfortunately, education has its fads. One of these is the wholesale adoption of the school of linguistics which claims it can teach any language without reference to grammar. As a result, many future writers enter college wholly ignorant of the foundations of their language. They do not know the meaning of "subject," "predicate," and "object"; "noun," "verb," "adjective," and "adverb" are equally unfamiliar terms and concepts.

College instructors or professors, ${ }^{1}$ teaching large sections of Freshman English-often the only course in Eng-

${ }^{1}$ Some institutions recognize the need for the best possible teaching at this level and insist on professorial attention to the beginner. They deserve conmendation. 
lish required of science and engineering majors-cannot begin to remedy this lack of grammatical background in a year. Graded on a curve, all but the most inept students succeed in passing this obstacle and go merrily on their way, completely unequipped to meet the future's demands. There is a good deal to be said in favor of restoring the old-fashioned college entrance requirement of Latin or Greek. A declined language (English is not considered such) forces one to learn grammar.

Scientific writing commonly shows the result of this lack of grammatical knowledge by such solecisms as: disagreement in number between subject and verb; change of tense within a single sentence; misrelated modifiers; and indefinite antecedents. A comprehensive list of common grammatical errors, with examples would require at least fifty pages of fine-print text.

What makes this lack of grammatical knowledge so important is that, unless caught and corrected early, the lapses become ingrained through repetition.

A first step toward better writing is the purchase of a good, easily understood textbook on English [1].

Further difficulties appear, at the college level, with the introduction of the "communication" concept of speech and writing. One major element of this concept is usage level, too often explained or defined in terms of purely academic differences. By improperly stressing the difference between spoken and written English, many teachers actually create needless difficulties for the student-writer.

We all wish to be understood when we speak. Accordingly, we adjust our usage level many times a day. If correct, usage level is dictated by the communications situation, as, for example, when we speak to a child. We do rhis almost unconsciously.

Our inability to make the same type of adjustment when we write stems from an error: choosing a usage level that matches the educational level of the writer or speaker, instead of the level of the reader-audience. As result of establishing the writer's intellectual status by his choice of usage level, the correct meaning of the terms "vulgate," "informal," and "formal" is lost.

We may dismiss "vulgate" since its built-in limitations make it a poor vehicle for conveying complex; abstract thought. Its paucity shows in the reduction of the concept of God to "the Man up There (pointing)."

While there are important differences between "formal" and "informal" usage levels, they are largely matters of style, not substance. Both are aspects of the broader category, Standard English, and this category provides a medium suitable for expressing any thought.

Confusion arises when "informal" is considered casual, almost sloppy, writing; while "formal" is held cssential to dignity and precision. The true distinctions lie in punctuation, sentence structure, and vocabulary. Formal English is punctuated tightly; informal, loosely.

A good example, common to scientific writing, is the difference in punctuating long subjects, consisting of a noun or phrase followed by modifiers, whose total word count exceeds six words. Formal usage calls for a comma between this type of subject and the verb; informal does not. For example:

Whether experiments testing the properties of earth glaze materials will succeed or not (,) depends absolutely upon careful control of kiln temperatures.

Formal sentences find the elements commonly omitted in informal writing (and almost all speaking) expressed. Typically, in formal sentences, we find repetition of prepositions and conjunctions in parallel construction, as follows:

The student working in this field must realize that the conduct of any given experiment may require varying techniques, from the simplest to the most complex, that the results may be inconclusive or partially obscured, and that the ultimate test of his scientific integrity is a completely accurate report of what he actually observed.

Formal English vocabulary includes words that belong to the written, rather than spoken, language and are associated with the literary or scholarly tradition. For an exaniple, read almost any passage in Dr. Samuel Johnson's Shakespeare.

Unfortunately, the average science-engineering major tends to have a limited background in literature (just as humanities and arts majors tend to have limited backgrounds in science and mathematics). As a result, bis judgment of good usage is biased. He adopts what he finds in most of his reading: a heavy, academic prosc. Worse yet, he clings to this style because he knows no other. Sadly enough, he finds acceptance for his bad writing; in fact, approval. The cycle runs full course and bad writing begets more bad writing.

The real danger in formal writing is that, unless handled properly, it readily deteriorates, becoming weak or dull. Dignity and learning are not synonymous with verbosity. Good writing, of any kind, is as simple as accuracy will permit. Yet how often do we find scientific writing disfigured by excessive verbiage and quantities of "gobbledegook"?

A common result of overdone formal usage is best described as "pretentious assery." Here we find many polysyllabic words, one heaped upon the other in hupe of achieving an effect of importance, all leading to an obvious or trivial conclusion. Witness this recent example of the genre:

When the quality of the atmosphere is degraded by pollution to the point that air of suitable quality is no longer instantly available, steps need to be taken to conserve the air as a natural resource [2].

What makes these 36 words such bad writing is that thoy do not convcy, in and of themselves, lle autlior's meaning. The reader must draw on his own knowledge of man's physiological needs to define the terms "air of suitable quality" and "is no longer instantly available." The conclusion, "steps must be taken to conserve . . ." is both misleading and painfully obvious. "As a natural resource"

\footnotetext{
' or governmentese, scientificese, or some other jargon.
} 
are magic words, included perhaps in hopes of securing a substantial Federal grant to support a program of air pollution studies.

Stripped to its essentials, which is the test of good writing, this paragraph could be written:

Man must have clean air to breathe at all times. To this end, we must prevent or remove sources of air pollution.

Which of the two statements just given conveys meaning more clearly to the reader?

The pitiful resülts of overdone formal usage in speaking were altogether too clear during the first televised interview about the success of Ranger VII. The lack of communication was so great that the magnitude of the achievement itself was lost; the audience's response was one of indifference.

\section{Faulty or Artificial Style}

We come now to the second cause of lack of interest in learning to write well, the deliberate inculcation of faulty or artificial style.

In the earlier stages of schooling, students are far too apt to cncounter the so-called "beautiful English" approach to writing. By compelling the use of an elaborate, dated style and florid word-choice, would-be educators hope to increase vocabulary and heighten the students' consciousness of the great flexibility and power of the English language. Instead, pure conformity for the sake of grades often lays an indestructible foundation for future bad writing.

Enamored of substitutes for simple words and schooled in circumlocutions, the student becomes a devotee of the "elongated yellow fruit" school of writing. To call it a "banana" would be unthinkable. To those infected with the e.y.f. virus, formal usage, as they conceive it, is the ultimate showcase for their wares. We can see the horrible result all too clearly in the example just cited.

Inevitably, we come back to grammar when we seek to establish what constitutes artificial or faulty style in writing. Like it or not, the model English sentence is: "John hit the ball." John, nominative-subject; hit, verb; ball, object; the, adjective (or definite article), modifying ball. Complete, succinct, exact. By adding clements to this simple declaratory sentence, we can change its grammatical classification to compound, complex, or compound-complex.

The particular classification is relatively unimportant; what is important is that we tend to ignore the fact that long sentences, with several dependent clauses, parenthetical phrases, and modifiers, make it difficult for the rcader to follow thought and grasp meaning. (This is a fairly good example in itself.)

Using a plea of accuracy, many scientific writers cram their sentences with qualification upon qualification, each a separate phrase or clause. The result is chaotic. The remedy, hard though it be, is to rewrite any such sentence, breaking it down into its component part3 [3].
When we compound the difficulties imposed by an already faulty background by forcing the student-writer to adopt the two major "canons" of scientific writing, we are certain to obtain bad writing, replete with long, unwieldy sentences.

The first of these canons, inherited from the period when the German universities dominated research (18801914), is the familiar: "Upon doing such-and-such, it appeared that (or it was observed that) so-and-so. . . ." This alien construction forces the use of passive verbs and a series of dependent clauses throughout the rest of the sentence; an almost ccrtain guarantee of muddied writing.

The second false god of scientific writers is the so-called impersonal style, as outdated and unnatural today as the professional uniform of horse-and-buggy days: frock-coat; high, stiff collar; cravat; tie-pin; and sideburns.

Using the pronoun "it" to achieve an impersonal tone makes for bad writing because the usual verb form used in conjunction with "it" is passive or intransitive. Both types are weak.

Consider these examples: it seems that; it is likely that; it is probable (possible) that; it is seen that; it is noted that; it is learned that; and so on.

Substituting "one" for "it" gives only illusory help." True, we may have active verb forms: one sees, one learns, one estimates, one observes, but dependent elements, following the relative pronoun, "that," will make up the balance of the sentence; an undesirable result.

Asked why they write this way, individual authors offer almost the same excuses: "Modesty dictates that scientific writing should be impersonal"; or, "A number of people worked on this project"; or, "That's the way scientific papers have always been written; I was taught to write that way."

Alas for belief! The first two statements can be demolished easily: modesty has nothing to do with statements of fact, and "we" is still considered the generally acceptable English pronoun for a group.

The third statement, except for the part about teaching, is untrue. There is no historical justification for the claim that scientific writing has always used the so-called impersonal style. Elimination of direct personal expression, a sine qua non of scientific writing today, is actually a perversion of the writing reforms introduced at the time of the establishment of the Royal Society in England during the 17th Century: ". . . the powerful movement to plain writing . . . (the Royal Society's) asking for a close, natural, naked way of speaking; positive expressions! [4]"

This demand succeeded in eliminating euphuistic (flowery) phrases and elaborate metaphors. The "ethereal coal" reverted to plain "sun"; "this mundane sphere" to "the world." Another benefit was the adoption of a plain, natural style instead of exercises in literary composition.

\footnotetext{
"One is not a true impersonal form; English has no equivalent for the French "an," or the German, "Mann."

"Authui's italics.
} 
This type of writing continued, particularly among the English, until the end of the 19th Century. Happily, it persists today, although in constantly diminishing amounts, among scientists who write and speak English [5].

Most unfortunately for scientific writing today, the injunction to "positive expressions" has lost all force.

"Whatever we may think of puritanism of language from a literary point of view, it favorcd the active and direct. That salutary influence has gone. A . . . symptom of the decline is the convention by which scientific experiments are described in the passive voice: 'A test-tube was taken,' not 'I took a test-tube'... . (The vice of the passive approach is) it creates the bureaucratic impression that things 'were done' and that nobody 'did' them. . . It is the sententious voice of boredom [6]."

Amen to that! Consider the following passage [7]. This is an attempt to communicate a thrilling adventure in scientific exploration of the ocean floor: a search for the lost atomic submarine, Thresher, and its crew.

“. . . Rather we describe the participation of marine scientists and their tools in the scarch for the wreckage of this ship, .... Clearly, such a discussion must start with some consideration of why one might want to make such a search at all.

". . . many ships plowed the area . . . while the aircraft, in addition, surveyed the area with radiological monitoring equipment. Negative results with this equipment eliminated the fear that some reactor accident had occurred, with associated high-level contamination of the sea. . . ."

I find it inconceivable that men with the intellectual capacity to plan and conduct elaborate cxperiments in support of complicated hypotheses, that men with the intuition to grasp the implications of both results obtained and what was not observed, should fail so signally when faced with the need to put things in writing. They cannot lack imagination. Yet we need only look at most scientific journals to find page after page loaded with scientific clichés, trite phrases, and stock cxpressions. Such usage is excused as a necessary shorthand, conveying meaning to those who will read it. It is nothing of the sort; it is plain intcllectual laziness, unworthy of those who indulge it.

The challenge is clear: How much can we improve our scientific writing? The answer is equally clear: A great deal.

Let us begin by rejecting the outdated, inadequate vehicle, justified as being impersonal, and readopt direct and expressive writing. Let us continue by seeing how concisely we can state our findings and conclusions and how simply we can express what we wish without any sacrifice of accuracy. When we do this much, we shall have made a great advance.

To change will not be easy. Habit makes all things palatable; in fact, desirable. But, if the scientific community and the editors of our journals and magazines insist upon change, if both insist upon high quality writing, change will.come. Let us prove to ourselves, if not to others, by working toward better written papers, that we are as progressive and open-minded as we often claim to be.

\section{The Elements of a Good Paper}

So far we have discussed some underlying causes of bad scientific (engineering) writing and have offered a few ways to eliminate these pernicious influences. Bearing these questions of style in mind, let us now consider the clements that go to form a well-written scientific paper.

\section{Time}

Working scientists and engineers need time to do a good piece of writing, far more than thcy usually allow. A practiced writer, covering a subject familiar in every detail, with all necessary references readily available, is able to turn out 3500-5000 words in three full working days. But to do so, he must ignore everything but the writing.

Most scientific writing, however, is done by people who cannot be classed as "practiced" writers. Nor do the authors of scientific papers have the benefit of the special situation just given. As a result, a reasonable time allowance is six working hours per page of finished script.

Many organizations, in spite of a "publish or perish" policy, do not allow an author "company time" for the necessary period of literary gestation and birth. Writers must snatch time where they can; pluck it from intervals in the working-day; and gain the main portion after-hours and over weekends. Both writing and work suffer from such a situation.

Lack of tine to write shows in many forms: typographical errors; inaccuracics in graphs, tables, and charts; and obvious mistakes in spelling, grammar, and punctuationall of which require expensive and time-consuming editing and correction. But most important, lack of time shows itself most clearly in defective organization, a major cause of bad scientific (and any other) writing.

\section{Organization}

Faulty organization is probably the easiest writing defect to remedy, given authors trained in the inductive-deductive reasoning process. Best of all, even slight improvement in organization will show to great advantage.

Obviously, it is neither possible nor desirable to lay down a fixed plan for all papers, but a logical scheme of organization is imperative and conventionally required. The normal "model" has the following form: Title, Abstract, Hypothesis, Experiment, Data Obtained, Evaluation of Data, and Conclusions. Engineering reports frequently add one more section, Recommendations.

Let us examine the desired content of each of these elements in the fabric of a paper.

Title: In a world plagued with problems of information retrieval, choice of title is increasing in importance. We should ask ourselves, "What am I reporting?" The answer should be as bricf as possible. Some good recent examples 
are: "Nemotode-trapping fungi [8]," "Dolphin telemetry [9]," "Alaskan earthquake of 27 March 1964 [10]," "Economics and the quality of life [11]," and "Strontium fixation by lime contained in soils [12]."

Do not start titles with such words as, Effect, New, Measurement of, Identification, or Considerations. These are not-key words; they give no effective means for classifying and identifying the real subject of a paper.

Abstract: Abstracts are a sadly neglected element of reports and papers, particularly since a number of retrie$\mathrm{val}$ and indexing systems carry them in full. A great many abstracts scem to be afterthoughts. A good number contain the only real meat in the paper; showing how much padding there is in the four, five, or even more pages of the article itself.

Actually, an abstract should be a concise summary of an experiment or investigation, its results, and the conclusions. It should also give a reader, who works in another field or discipline, a reasonably accurate idea of the subject-matter under discussion.

For a sound start, pick out the "topic sentence" in each paragraph of the paper [13] (this, incidentally, is a fine check on the paper's overall organization), and boil the resulting collection down to size. The fewer words a journal or service allows, the more difficult it is to write a good abstract. Good headline writers are hard to come by and, in a sense, an abstract is a headline. Remember that 1000-1500 words is a synopsis or digest, not an abstract.

Mathematical papers, with their minimal amount of text, are an exception. Here, the derivation and function of the principal equation may well serve as the abstract.

Hypothesis: Under this heading, we find place to explain the reasoning that led to performing a certain experiment, or what we hoped to deduce from making a given set of observations. Here is the place to present relevant theory, related work in the field, and other broad, general considerations.

After setting out one's own hypothesis, what is wrong with summarizing the state of knowledge in the field in some such manner as: "Early experiments-established ...", giving credit and references in a single footnote? This approach eliminates the distracting shift from text to footnote and back again that the present practice of giving individual names in the text and citations in the footnotes requires.

True, there are people who did important work; they should certainly receive credit-but in a footnote, where references belong. This method would also eliminate torturous sentences forced by another type of referencing:

The first known publications of this unusual fading in equatorial latitudes were presented by Rao and Sonayajulu (1949) and Osborne (1952) where the former article dealt with observations on All-India Radio broadcasting, and the latter with vertical-incidence pulse experiments in Singapore.

Revised to meet the suggested standard, this sentence would read:
The first known publications of this unusual fading in cquatorial latitudes dealt with observations of All-India Radio broadcasting," and with vertical-incidence pulise experiments in Singapore.?

Treatment of chronological stages of development should summarize results and thought, not bc a detailed recital of names, places, and techniques; its conclusion should be the present generally accepted theory.

If a reader is not familiar with the field, footnotes will lead him to learn what he needs to know, assuming he is interested. If he is familiar with the research area under discussion, particularizing is needless and almost insulting. No matter how impersonal the mode of expression employed, the writer who particularizes is showing off; saying: "See how much I know."

Once theory is set forth, if we describe the relation of our own hypothesis to the general view, or to some particular aspect of accepted theory, we clearly establish the purpose of our experiment (or observations) for the reader. This leads naturally to the discussion of what our experiment accomplished.

Experiment (Observations): The importance and value of a good description of an experiment or the technique of observations cannot be over-emphasized. Facts or data depend on what was done and how it was done; conclusions are the product of facts. All too often, this portion of the paper is fragmentary, incomplete, or confusing.

Remember, as the author of the paper describes, readers cannot be as familiar with the technique, equipment, and approach used in a given experiment. Significant steps are often omitted; differences in procedure and modifications of equiment are often lost in a maze of generalities. This type of omission leaves readers without any firm basis for comparison to similar experiments in the field or for judging the soundness of techniques and methods. Carried far enough, it will make them question the reliability and accuracy of the data obtained.

It is in this part of scientific papers, perhaps more than any other, that the passive, weak sentence, the result of following the "canons" of scientific writing, seems to proliferate. And it is here, of all places, that writing should be clear and direct. Here is the best place to "wring-out" surplus verbiage.

Nothing is gained, for example, by the familiar: "A series of experiments, designed to establish (confirm, refute) such-and-such, using . . ." followed by a description of equipment or apparatus, often couched in two- and threepage paragraphs. Such expressions as "designed to" are redundant since any experiment should have a definite purpose.

Normally, if the Hypothesis section is written clearly, there will be no question as to the purpose of experiments or obserwations. In rare instances, where a-definite relationship between experiment and theory is not apparent, this relationship can (and should) be brought out before proceeding with description of the experiment itself. 
This approach meets the communication requirement of telling the reader "what" and "why"; he certainly knows "who" from the by-line.

Sharpen the entire write-up by separating experiments into their component parts. Begin with a simple statcment, such as:

A series of experiments to test this (our, my) hypothesis began December 6, 1960, and ended August 8, 1964;

or,

During the period of total eclipse of the sun, we made observations of the solar corona every ten seconds.

At this point, present the all-important "how." This calls for a description of the apparatus or equipment and of the technique and procedures. An approach which recommends itself is:

The apparatus used for these experiments is identical to that decoribed (or used) by ..."

with a footnote for appropriate citations. This statement can readily be modified to fit circumstances by such terms as "new," "essentially the same as, but," "slightly modified," "greatly modified," or, "differing" to a greater or lesser degree.

Follow whichever form fits the situation immediately with the magic notation: Figure 00 . Here is the place where a picture saves words and may be worth the proverbial 10000 .

A good, clear diagram or picture, with readable labels, having any significant changes in conventional or traditional arrangement of components well-marked, is of inestimable value. To the reader, it gives an instant grasp of the physical conditions of the experiment; to the writer, the means of limiting comment to significant portions of the equipment. For best results, figures should be fitted to the text, positioned to allow ready reference between text and illustration.

Describing how observations were made need be no more difficult. A case in point is the clear photograph and diagram, printed side-by-side ("paired shot"), used to illustrate the camera-telescope hookup for taking pictures of the total eclipse at the Danger Islands site.

Techniques or procedures present a more difficult writing problem since they are infinitely variable. Any general prescription for handling this aspect of an experiment would be too limited for general use. Suffice it, sentences must be kept short and active. A promising method is that used in any good operational instructions manual; army weapons manuals are another approach; some cookbooks are quite good. Or, for choice, break the procedure down into steps, each covered by one or two paragraphs.

Whatever the method followed, avoid lengthy, unbroken blocks of text. According each step a paragraph or two makes for easy reader-reference between portions of the text and tends to promote direct statement in writing.

Data (Observations): With the means tidily described, we come now to the "end" of an experiment or observations, the data obtained. If technique and apparatus were treated properly, the natural flow of comnunication and thought leads to a direct, active statement that the experiment produced this, that, or the other result; or, that observation(s) shows this, that, or the other thing. Not, "it was observed that." Again, a series of short paragraphs will clearly establish just what did happen or what was observed.

Here too is a place for good illustrations. Tables, graphs, strip charts, and photographs of records, if large enough to read easily, will help clarify statements and verify findings. "The reader also gains the means of judging the accuracy of observation, of comparing the author's results to any others he knows of, and of recognizing the validity of the conclusions that follow.

Cover any interrelationships between physical phenomena in separate paragraphe--eithor directly following the description of a particular phenomenon, or, depending on connection, after enumerating the facts. Guard against interpretation of the whole body of data (assuming that this is desircd) at this point. Reserve this interpretation for the section on evaluation which should follow immediately.

Evaluation of Data: Major weaknesses in presenting an evaluation of data are the excessive use of text-breaking references, ${ }^{\overline{0}}$ qualification to the point where no definite position is taken or apparent, and dilution of thought and conviction by the impersonal approach.

Qualification is important and necessary but it should be specific. Too often we find statements about data hedged with equivocations, such as: "assuming that," "if the recording instruments were working properly (or, calibrated properly)," or, "allowing for an observational error of approximately $\pm X$ percent." This type of qualification, when necessary, could well be presented as unnumbered footnotes, distinguished by the conventional symbols. True qualifications, however, have a direct relationship to observation and data and should have the same place in the text as any other modifying element in English: as close to what they modify as possible.

Qualification (or weakening) of the author's interpretation of data, using the forms, "it would seem" or "it seems reasonable to assume," is all too prevalent. If an author is qualified to write about a certain subject, there is no valid reason why he cannot write, "It seems to me," or, "T. think" (or, believe), stating his positioir clearly.

Let us postpone discussion of "dilution of thought and conviction by the impersonal approach" for a moment.

Conclusions: In this section of scientific papers, we find horse-and-buggy writing supreme. The same comments about equivocation obtain, but dilution of thought and conviction by the impersonal approach is even more harmful to the author and the reader.

Conclusion, in logic, is defined as a proposition concluded or inferred from the premises of an argument; it is also defined as a deduction or inference. Conclusions in

see Hypothesis. 
scientific writing partake of the nature of both of these definitions. As such, conclusions should be expressed directly and plainly.

One of the best Conclusions, found in a paper which described exhaustive tests of a new type of engine, consists of four words: It does not work. Unfortunately, most scientific writing deals with subjects of complex nature. A four-word sentence will hardly serve to present the conclusions. We are compelled to go into detail," and we tend to handle the writing relatively badly, so that our conclusions are often obscured or even lost.

A recent example of a superior Conclusions section consisted of short, numbered statements. Each began with the words: "We conclude"; none was over 25 words long. There were four such statements; each readily comparable to the preceding sections of the text.

Another example, perhaps a model of its type since it covers the text of an entire book, is:

The principal conclusions of this book are: (1) The earth and other terrestrial planets were formed at much lower temperatures than were generally thought to be the case up to the present time. (2) A more uniform distribution of iron throughout the silicate phases of the earth existed in the past than exists now, and the iron core of the earth bas been formed, at least partly, during geologic time [14].

Now, let us consider the main reason for poorly written Conclusions: the pernicious dilution of individual thought and conviction by the impersonal approach.

It is high time that we stopped using this style of writing. First, it creates endless grammatical difficulties for the writer. Second, it is wholly at odds with the concept of the valuc of the individual held by Western philosophy. It is unreasonable to insist on a style of writing that obscures, rather than reveals, the origin of an author's thoughts; the position he takes from conviction.

Technological advances have given us research and production tools undreamed of in the past, enabling us to achieve equally uriforeseen results. Much of today's work is just as new and original as. the discoveries of the pioneers in the Age of Science. Research and industry depend increasingly on individual thought to expand horizons and explore new fields. This, in spite of the ubiquitous committee. Why should the individual's role in science and engineering be suppressed? Whom are we trying to deceive by following an outmoded convention?

Or, as has been suggested, are we so afraid to take a stand as individuals that we take shelter behind the convention from challenge or criticism? Are we then less daring, less confident of our abilities than the scientific trailblazers of the past? They did not hesitate to write: "I think," "I believe," "I conclude [14]." And, we are the inheritors of their knowledge.

I firmly believe that using the impersonal approach seriously weakens the force of any Conclusions section. If the

- Frequently unnecessary if the paper hat had good organizalon disd we were not forced to deal with entranoous olements in this section. steps of the scientific method, hypothesis, experiment, and conclusion, are rigidly observed, and the evaluation of the data or observations is accurate. Conclissions will be facts. Nothing is more impersonal than fact.

Conclusions need not be a series of "l"-headed sentences. There are many places where this approach is neither desirable nor best. But, in the heart of the paper, where all the threads are pulled together and summarized, "I," the writer, has a rightful place."

Insistence upon the impersonal approach, with the consequent elimination of the individual, carries with it another danger: excessive veneration and dependence upon "authority." How far we have already gone in this direction is altogether too plainly seen in readers' and editors' comments and questions, appearing on manuscripts or report sheets.

Authoritarianism, an attitude common to the Aristotelians, seriously hampered the emergence of new knowledge and original thinking during the Renaissance. It will always continue to do so. Authority needs constant retesting as we advance, witness the major changes in theory in almost every field during the past decade. Lack of freedom to challenge authority, particularly in our journals, will inevitably lead to scientific orthodoxy, a most abhorrent concept.

Recommendations: Recommendations are perhaps more important to the engineer than almost any other portion of a piece of writing. They are equally important to the scientist who is making a proposal or reporting to a sponsor of a project. Depending on how well we can write this section, we obtain financial support or professional recognition.

The key to successful recommendations is constant attention to the audience-reader's level of knowledge and attitudes. We must ask ourselves: what does the person who will read this want to learn? Commercial possibilities? Progress in research? Future probable developments? The list is infinite but we must supply both the questions and the answers.

If a paper is properly organized, formulating the answers is not too difficult. They follow naturally from our Conclusions. Remember, however, that the form of the answer, the words and style in which it appears, must depend entirely on the reader for whom it is intended. No matter who the reader is, recommendations should be direct, clear, and as brief as possible. Again the numbered series is a good scheme of arrangement.

Above all, recommendations must deal with costs, where necessary. The more accurate the figures we can supply, the better chance we have of having our recommendations accepted and put into action. Take the time to get cost figures from whatever source can supply them; check them carefully and consider any recent changes in the price of materials or items of equipment before making any projection or cost estimate.

"Otviously, "we," if several people or a group did the work. 


\section{SUMMARY}

I believe that the suggestions I have made in this article, if fol!.owed, will help scientists and engineers to communicate better than they have in the past. This can enhance professional reputation, assist advancement, and gain financial support for authors and their parent organizations.

More important, the ability to communicate offers special satisfactions: knowledge that work and thought are accurately and well presented; that clarity and conciseness make any contribution to knowledge easier to grasp; and that good communication benefits the entire scientific community.

\section{REFERENCES}

[1] P. G. Perrin, Writer's Guide and lindex to Einglish, iev. ed. New York: Scott, Foresman, 1950. R. M. Gorrell and c. Laird, Modern English Handbook, 3rd ed. Englewood Cliffs, N.J.: Prentice-Hall, 1963. C. C. Fries, American English Grammar. New York: Appleton.Century Crofts, (Protional Cunall of Teaciner's of English Monograph 10), 1940. H. W. Fowler, A Dictionary of Modern English Usage, rev, ed. London, England: Oxford, 1926.

[2] "Air conservation," AAAS Bull,, p. 1, June 1964.
[3] R. Gunning, The Technique of Clear Writing. New York: McGraw-Hill, 1952.

[4] V. S. Pritchett, N.Y. Times Literary Marazine, quoting A. N. Jeffares, "Language, Literature and Science," Leeds University Press, England, 1960.

[5] cf. J. Priestly, Directions for Impregnating Water with Fixed Air; J. Dalton, On the Absorption of Gases by Water and Other Liquids; M. Faraday, The Tides, Appendix $\mathrm{A}(2) ; \mathrm{C}$. V. Boys, Soap Bubbles and the Forces Which Mould Them; J. L. R. Agassiz, "The Silurian Beach" in Geological Sketches; C. R. Darwin, "The struggle for existence" in Origin of Species; E. Fermi, Elementary Particles, Appendix 4; and H. C. Urey, The Planets: Their Origin and Development.

[6] See Pritchett [4].

[7] Selections from two consecutive paragraphs. F. N. Spiess and $\Lambda$. E. Maxwell, "Search for the Thresher," Science, vol. 145, pp. 349-350, July 24, 1964.

[8] Science, vol. 144, p. 382, April 24, 1964 .

[9] Science, vol. 145, p. 296, July 17, 1964.

[10] Science, vol. 145, p. 261, July 17, 1964

(11] Science, vol. 145, p. 117, July 10, 1964.

[12] Science, vol. 145, p. 154, July 10, 1964

$[.131$ G. P Perrin, Mritess Gevidi and Index to Enghsh, rev. ed. New York: Scott, Foresman, 1950, pp. 185-187.

[14] H. C. Urey, The Planets: Their Origin and Development, New Haven, Conn.: Yale University Press, 1952.

[15] Note [5]; excepting E. Fermi and H. C. Urey. 


\section{APPENDIX B}

"A World Without People" (Copyright 1969 by Institute of Electrical and Electronics Engineers, Inc. Reprinted with permission from IEEE Transactions on Engineering Writing and Speech, October 1969, Vol. EWS-12, No. 3, PP 79+.) 


\section{A World Without People \\ Using the Personal Pronoun to Improve Technical Writing \\ GERALD I. . COHEN, MEMBER, IEEE}

\begin{abstract}
We shall never improve the general quatity of technical and scientific writing until it is liberated from the unwritten rule that prohibits the use of personal pronouns. This superstition made possible-if not inevitable-the development of the "technical style" of writing, the most unreadable and unnatural prose in the literature of the English-speaking world.

Many of our problems in technical writing-verbosity, obscurity, pomposity, awkwardness, and a dozen other ills-could be relieved or eliminated if writers would accept the idea that personal pronouns are as much a natural part of communicating ideas on paper as they are in talking. Will that day ever come?
\end{abstract}

TI EXPLAINING to women why he wrote a book on economics, Intelligent Woman's Guide to Socialism and Capitalism, Bernard Shaw said:

... all these books [ on economics] are addressed to men. You night read a score of them without ever discovering that such a creature as a woman had ever existed. In fairness let me add that you might read a good many of them without discovering that such a thing as a man ever existed.

It struck me that no truer thing could be said about the writing in many other fields besides economics. If we assume that the existence of human beings is signalled by referring to them in various ways-he, man, girl, I, we, nobody - then in scientific and engineering writing no such creaturcs cxist. Why? I believe that in solving the mystery of this disappearance we shall uncover the reason why much of the writing in business and industry is so bad. And inevitably our exploration will lead us to consider another question: Is the absense of hunian beings a symptom of bad writing or a cause of it?

Is it merely accidental that engineering prose without personal pronouns is usually stilted, pompous, verbose, obscure, or perhaps just dull? Consider, for example, the two writing styles that follow. The first is a passage from The General Theory of Relatioity by Albert Einstein. It is widely agreed that this theory is one of the most complex ideas ever conceived, yet Einstein writes about it in a perfectly natural, conversational tone, repeatedly ignoring the "law" against the use of "I" in scientific literature. The second is a passage taken from a typical technical report on a relatively simple subject. But here the writer has strictly obeyed the injunction against personal pronouns-mark the effect it has had on his language.

Manuscript received March 19, 1969.

The author is with the Systems Publications Department, 'IBM Corporation. Poughkecpsie. N,Y, 12602.

\begin{abstract}
by Albert Einstein
I am standing in front of a gas range. Standing alongside of each other on the range are two pans so much alike that one may be mistaken for the other. Both are half full of water. I notice that steam is being emitted continuously from one pan, but not from the other. I am surprised at this, even if $I$ have never seen either a gas range or a pan before. But if $I$ now notice something of bluish color under the first pan but not under the other, I cease to be astonished, even if I have never before seen a gas flame. For I can only say that this bluish something will cause the emission of the steam, or at least possibly it may do so. If, however, I notice the bluish something in neither case, and if I observe that the ore pan continuously emits steam while the other does not, then I shall remain astonished and dissatisfied until I have discovered some circumstance to which I can attribute the different behavior of the two pans.
\end{abstract}

\section{by a systems engineer}

This sequence of operations is usually performed a number of times. During the first few iterations, the functions are likely to be done in a rapid and inexhaustive manner. The analysis is performed by arithmetic approximations in an effort to eliminate the majority of unsatisfactory system configurations. These first iterations of this cyclic method are, therefore, brief feasibility efforts. The later efforts usually are quite detailed. It is during these later study cycles that the procedures are defined more clearly, and the data is gathered and reduced to values which describe the total system loads as accurately as possible. The program estimates are reaffirmed and reevaluated; and, detailed knowledge of system equipment is acquired. The analyst must generally resort to the simulator program by this time. The final study efforts are usually done to refine the proposed system techniques. The number of iterations and the overall time to perform such studies will vary widely; however, a large number of itcrations does not necessarily indicate....

Now, I contend that writing devoid of personal pronouns, produces language that is unnatural because it is a violation of the way people instinctively conmunicate ideas. "Writing is mnemonic in its effect," said American linguist Donald Lloyd, "It must remind us of our speech or we cannot read it."

Impersonal writing has a cold tone because it is cold. It is the same thing as turning your back on a person when you speak to him. Why should that person listen to you when you won't pay him the courtesy of looking at him? And why should a man read your writing when you won't pay him 
the courtesy of addressing him? Rudolf. Flesch explained it this way:

Keep a running conversation with your reader. Use the second-person pronoun whenever you can. Translate everything into you language. "This applies to citizens over 65 " = "If you'rc over 65 , this applies to you." "It must be remembered that" $=$ "You must remember." "Many people don't realize" ="Perhaps you don't realize."

Always write directly to you, the person you're trying to reach with your written message. Don't write in mental isolation; reach out to your reader.

Good advertising has just that quality. Here, for example, is the copy from an ad that ran in Datamation, a popular magazine in the computer field.

Let us take you down memory lane.

Before there could be ferrite cores

thure had to be ferrites.

Philips of the Netherlands developed the first

ferrites.

Then Philips uncled [uncle as a verb] us

and together we made the first 30 mil cores.

Then we made the first 20 mil cores.

Then we learned to string them before

anyone else did.

Then we learned to string them more economically than anyone else could. (so economically that in 1964 we brought the price of memory stacks down $65 \%$.)

Next we'll tell you what we've been doing for you lately

\section{FERROXCUBE CORPORATION OF AMERICA Saugerties, New York}

Even in economics, it was never a custom to write impersonally-until recent times. John Ruskin wrote as follows in the $1860 \mathrm{~s}$ :

It is unwise to pay too much, but it is worse to pay too little. When you pay too much, you lose a little money-that is all. When you pay too little you sometime's lose everything, because the thing you bought was incapable of doing the thing it was bought to do. The common law of business balance prohibits paying a little and getting a lot-it can't be done. It you deal with the lowest bidder, it is well to add something for the risk you run, and if you do that, you will have enough to pay for something better.

Perhaps one of our mudern economists would complain that such a style is too elementary when dealing with "the complex concepts of economics." One of the best replies to this argument was made by John Kemeny, the eminent mathematician, in the foreword to his very readable book, A Philosopher Looks at Science:

I will make every attempt to keep this book readable and yet to make my statements precise. I will try whenever possible to use a group of small words in place of a Big Word. . . Of course, there are a substimliill number of readers who judge how deep a book is by (llc number of Big
Words occurring in it and by how difficult it is to understand various passages. To these readers I can only say that $I$ hope they will find my book extremely shallow.

Once again, we note the natural use of "I." How did the superstition regarding the use of personal pronouns in technical exposition come about? In their book Tcchnical Reporting, Joseph Ulman and Jay Gould speculated as follows:

Most technical reports and papers describe ideas or physical events or physical objects. Quite properly, the observations are supposed to be accurate and objective, and the observer is thrust into the background. Whieal you report on an investigation, your reader is interested in what you found out, not in you. So far, so good.

Based on this perfectly sound notion a convention has grown up that the technical writer must always rcmain completely impersonal; in particular, that he must never use the flrst-pérsun singular pronoun, $I$. As a result, most teclunical writing is much more impersonal and much drier than it really needs to be.

... You can sound egotistical and subjective without ever uttering an $I$ or a We. Conversely, you can maintain the proper tone of modesty and objectivity even though you do say these words. If you will use the first-person construction judiciously, you will often find your writing task eased, because you will be speaking naturally; and your audience will find the result clear and pleasant to read.

This point is worth amplifying. Here arc four sentences: two with first-person pronouns, on the left; two without, on the right.

I saw that she had red hair.

She is beautiful.

I clocked the printer at 1800 lines a minute.

This printer offers tlie musi profitable operation of any now available.

Now an engineer brought up on the superstition that firstperson pronouns indicate subjective thinking would say that the statements on the left are "nonobjective" while those on the right are "objective." If anything, the very reverse is true, for the sentences on the left are statements of fact-observations. And those on the right, on closer examination, are opinions: she may not be beautiful to us; a competitor might dispute the claim about the printer. This illustrates the fallacy of mechanically associating personal pronouns with subjectivity and egotism. Apparently this matter haunts the students of today, and few professors handle it the way Canbridge lecturer F. L. Lucas does:

I am sometimes asked by pupils, "What shall we do about expressing personal opinions? Should one say 'I'?" I do not see what else to say. "We" sounds like an old-fashioned leader-writer editorial writer. "One" is often clumsy, and "one's" still clunisier. "The present writer" is often pormpous; nor was I much drawn to a facetious variation I was once offered-".the present scribe."

"I" seems the only frank and honest form; it will not make a writer seem egotistic, unless his general tone is that. Actually it is far more modest (and often more truthful) to say "I cannot admire this poem" than to say "This poem is 
worthless," with the assurance of a President of the Immortals conducting the Last Judgement.

Of course, we can't overlook the role that modesty-perhaps false modesty-plays in this problem. Bergen Evans touches on this point:

Some people seem to feel that $I$ said, $I$ think, and so on, are fighting words, and retreat into the passive construction in order not to inflict themselves on other people. Some think they know exactly how often $I$ can appear per thousand words without giving offense. There is not a word of truth in any of these theories. Anyone who is only interested in himself is a bore, and he does not become less of a bore by using passive verbs. Anyone who is interested in the person he is speaking or writing to may use the word $I$ as often as he likes. No one will ever see anything egotistical in I like what jou did and I wish you would tell me how I can pay for it.

This is getting to the central issue, the main harm that the avoidance of personal pronouns causes: the overuse of the passive voice, which is the characteristic voice of teclunical writing. This is how it works. The writer has a thought in his mind; let's say that it's something like this:

We can write a program to do your accounting. It will take us about 6 months.

Now, would he express himself on paper in more or less the same words? No. His reasoning, whether he realizes it or not, goes something like this. "I can't start a sentence with we. It's not proper." Thus inhibited, and with the blank paper staring at him, he slips into a passive construction:

The accuunting program can be written in 6 months.

And from that version, it's but a short way to the injection of the deadly abstract language of the next stage:

Implementation of the accounting function can be accomplished on a 6-month basis.

And we arrive at the typical style of expression in technical writing. Those who inflict this verbal dysentery on others walk about serene in their belief that they have achievedwithout too much trouble-a dignified style of writing. Imagine 150 pages of:

The I/O LS/MFT is modified to test for drum interruptions prior to normal interruption interrogation to reduce the overhead required to process the QED in the rollout/rollin channel program. This is accomplished using the fact that the drum is required to be alone on the selector channel it is attached tn. Conversion into the intermediate system range required implementation of the QED systems, and dual operation testing until complete utilization of the concept is feasible. Conversion requirements for this expanded system were considered during intermediate system implementation. These three approaches conceptually function as their-relative approaches using LARD for new applications.

In the face of this, I can only wail as did editor Samuel $\mathbf{T}$. Williamson in condemning the language of social scientists:

Such pedantic Chostaw may be all right as a sort of code - language or shorthand to circulate among initiates, but its perpetrators have no right to impose it on others. The tragedy is that its users appear to be under the impression that it is good English usage.

Occasionally, there is a ray of hope-sometimes from the unlikcliest sources. The Army Rockct and Guided Missile Agency put out a Techuical Manual Writing Guide in which it said:

... Most people seen to háve the idea that all Army manuals are written in dry, impersonal, third-person text. This is not true. According to AR 310-3, personal pronouns (I, we, etc.) are appropriate in training literature. . When "we" or "you" is used, the AR points out, a direct style is obtained, and the reader is made aware that the subject is intended for him personally.

The magazine Science instructs its contributors as follows:

- Choose the active voice more often than you choose the passive, for the passive voice usually requires more words and often obscures the agent of the action. Use first person, not third; do not use first person plural when singular is appropriate....

Under "Information for Authors," the highly technical magazine Simulation advises:

SIMULATION favors an easy, natural style of writing. This means that the author may, when appropriate, refer to himself in the first person and address the reader as you. It means using the active voice when it is natural to do so, and avoiding such artificialities as $/ t$ is felt . . . It is believed . . . It is suggested. . . . Finally, it means writing simply, directly, clearly-writing to be read!

And there is almost unanimous agreement by writers on the subject of technical exposition that avoiding personal pronnuns lures the writer into the passive voice habit. Margaret Norgaard, a technical editor at Remington Rand, puts the injunction against personal pronouns under "Rules to be Ignored":

Technical writing should be impersonal and completely objective without the personal pronouns we, you, $I$, as subjects, and without the intrusion of personal opinion or personal philosophy." As a matter of fact, the process article, which tells someone how to do something, is often clearer if couched in the second-person form.

First, you adjust the dial at the top of the machine to the temperature you wish. Then you turn the switch marked "on-off" to start the machine.

The research report in particular may be a personal narrative and in all forms of the technical article the use of we, you, they, or even I may be effective. Too meticulous an avoidance of the personal form may lend to overuse of the passive voice: As for opinion and philosophy, their inclusion in disciplined form makes possible an expression of a writer's personality and forms a bond with the reader.

Too many teachers, who never tried to learn whether this convention had any sensible justification, mindlessly foist it on their uncritical students. Readers of this article may recall 
incidents like the following. The instructor of our freshman English class asked us to prepare a library paper such as the one starting on page 429 of the Harbrace College Handbook, our textbook. In his instructions he warned us:

I don't want you to use any personal pronouns in your paper. I want it to be objective and detached.

Unaware of the sacredness of that precept, I mentioned that the example paper in the book contained such forbidden words, as did indeed the rest of the handbook. The response was a frosty look plus more talk about "scientific objectivity."

Probably nothing will change his attitude or that of those like him. Hulon Willis, Chairman of the English Department of Bakersfield College, had them in mind when he wrote in Structure, Style, and Usage:

Students are sometimes advised not to use the indefinite second person in their writing on the grounds that it is too informal. Virtually all the writing required of college students, however, is on an informal or semiformal level, and in such writing use of the indefinite second person is wholly permissible. In fact, there are few writing situations on any level in which such use is wrong. You may confidently use the indefinite you when it seems natural to you.

On page 203 of the same book, he puts the case even more strongly:

A similar illogical precept sometimes given is that the indefinite you should be avoided. For example, sometimes this mode of reference is insisted upon: "When one is preparing a term paper, he should recheck his direct quotations for accuracy." And this mode of reference is sometimes thought to be inappropriate: "When you are preparing a term paper, you should recheck your direct quotations for accuracy." The truth of the matter is that in most writing situations the use of indefinite you is preferable to the indefinite one. It is a more natural and a warmer usage. The objection that the reader will not be able to tell who is meant-he personally or people in general-is not valid. Many students become afraid to write naturally because they are hounded with such insignificant, or downright false, precepts.
1 mentioned that the two evils of technical writing usually go hand in hand: where you find impersonal writing, there you also find the passive voice with its handmaiden, overabstraction. English critic V. S. Pritchett argued the case in a letter to the New York Times Book Review of May 10, 1959:

A minor but ubiquitous symptom of the decline in good scientific writing is the convention by which scientific experiments are described in the passive voice: "A test tube was taken," not "I took a test tube." The former construction maintains the impersonality of science; the latter lets in the frivolous and unstable ego.

A correspondent takes this up in the Times Literary Supplement and says that to write "I weighed out 10 grams of aspirin and dissolved them in as little water as I could" would be deplorable in a research paper. The desirable plain scientific statement would be "Then grams of aspirin were dissolved in a minimum volume of water." Possibly; possibly, not. The terrible thing about that second sentence is that its infection has spread in all its falsity beyond research-into politics, religion, public statements, film scripts, journalism. It creates the bureaucratic impression that things "were done" and that nobody "did" them. . I think I might have profited by my scientific education if science had dropped the passive voice. It is the sententious voice of boredom. A pen was not filled with ink this morning, I filled my pen:

A world without people in writing has brought us a style without grace.

We must abandon a convention that has debilitated our technical literature. We must stop writing in a mental isolation that carries us to the never-never land of abstraction and multitudinous syllables with meager sense. We must return to a masculine English in which so many ideas are delivered in almost an equal number of words, in which the words used are free from affectation and pedantry. We must stop being afraid of personal pronouns and realize that nothing binds our reader to us like directly addressing him. If this is done, everything else will fall into place: nouns that are more concrete; verbs that are more active; language that is more fitting as a vehicle for conveying living thought. 
APPENDIX C

"Verbal Pollution" (Copyright 1979 by Institute of Electrical and Electronics Engineers, Inc. Reprinted with permission from IEEE Transactions on Professional Communications, September 1979, Vol. PC-22, No. 3, PP $165+$. 


\section{VERBAL POLLUTION}

Frank R. Smith

Abstract: Pretentious, wordy writing occurs because written English is different from spoken English and because writers have developed bad habits. Four specific varieties of verbal pollution are (1) the smothered verb, (2) the freight-train adjectival phrase, (3) the indiscriminate use of jargon, and (4) the habitual hedge. Once their causes and symptoms are understood, these faults are easy to detect and eliminate.

Why is it that a normal, intelligent, straight-thinking citizen becomes a pretentious idiot the instant he picks up a pencil?

We see examples of this strange transformation every day: Someone says to us on the phone, "I had to stop the test because of so and so," but when we ask him to write it down, we get "The undersigned, as the duly designated, cognizant authority (reference a), was constrained to terminate the on-going experimentation in view of the fact that...."

This kind of verbal pollution is committed thousands of times a day even though nearly all engineers and scientists have had one or more formal college courses, short courses, and seminars on "clear communication" or "effective expression" or "technical writing." All such courses stress the use of short sentences and simple words. Most of them advise students to "write like you talk." Some of them urge the use of personal pronouns like "we" and "you" even in formal technical reports. Not one of them recomnends the use of "the undersigned" or any of the other garbage phrases that infest our writing. So why do we go on polluting the paper that is one of our essential products?

\section{REASONS FOR VERBAL POLLUTION}

If you have ever given any thought to this question -- and nearly all of us have, briefly -- you will have come up with one or more of the following answers: We write the way we do because

- our bosses (or our customers) insist on it;

- our readers are also technically educated and will easily understand us;

- we know our readers and they would be shocked at anything less formal than "the undersigned";

- we have been taught for years to be technically precise and thorough in everything;

- we are expected to be objective and impersonal in our work;

o everything we read sounds even worse than what we write.

There is the usual grain of truth in each of these excuses, but individually and collectively, they are mostly hogwash. We write the way we do for an entirely different set of reasons: 
because of the differences between spoken and written communication; - because of fear, insecurity, ignorance, laziness, lack of pride, lack of ambition, and similar common frailties that are difficult to admit to.

Spoken communication has several characteristics that written communication lacks: (1) It takes place immediately; (2) it normally allows instant feedback; (3) it is impermanent; (4) it is flexible and informal; (5) it is usually directed to a known and limited audience; (6) it is supported by visual and auditory cues that greatly enhance the words themselves; and ( 7$)$ it is delivered at a rate that is controlled by the speaker.

In contrast, written communication can be read at any time, in any place, by an unknown audience, at a rate that is determined solely by the reader; that is, once the written document leaves the wriler's liauls, il is beyond his control for all practical purposes. Furthermore, it is often the only link between the writer and the reader and thus it determines the reader's attitude toward the writer. There is usually no effective feedback that allows the writer to clarify and amplify his words, and as a substitute for the marvelously flexible human voice and the facial expressions, gestures, and other tools used by the speaker, the writer has at his command only a few rules of grammar and a few marks of punctuation -- period!

Partly to compensate for these differences, our written language has evolved into what has been aptly termed an artificial dialect of spoken English. For example, we try to make up for the lack of feedback by including every possible qualifying thought and every last piddling detail. We try by using big words to ensure that our readers will have a good opinion of us and will respect our soaring intellect. At the same time, we try to show our modesty by referring to "this office" or "the writer," and so on.

Furthermore, the formalities of grammar, speling, and punctualiuil, which are of little or no consequence in speech, assume great importance in writing because the accuracy of the communication depends largely upon them. Unfortunately, the study of these mechanical details is one of life's drearier pursuits, and most of us have given it only enough attention to memorize a few false rules, such as "Never end a sentence with a preposition."

Nevertheless, we might be able to overcome most of these limitations if we were not victims of our own human nature. If we ever got beyond the stage of paying lip service to the need for good writing; if we ever objectively looked at our own writing with the same critical eye that we cast upon writing that we disagree with; if we ever took the trouble to ask a buss or a customer what lind of writing he really wanted -- if we did any of these things, we could begin to cut down our verbal pollution.

\section{KINDS OF VERBAL POLLUTION}

Although most forms of verbal pollution are pretty obvious when we see them in someone else's writing, they are a little more insidious in our own work. I now examine several common forms of pollution to explain the process by which the problem arises, the reasons why it does, and -- briefly -- the dangers or losses that ensue from it. I look specifically at the smothered verb, the 
freight-train adjectival phrase, the indiscriminate use of jargon, and the habitual hedge. I also include a few more or less self-evident words of advice on how to avoid these faults.

\section{The Smothered Verb}

Many years ago I published an article called "Patterns of Word Formation" [1] which outlined several ways the English 1 anguage can create new words. The most common patterns for forming technical words are

- the addition of words or parts of words to a root word (e.g., "flame" + "able" or "flame" + "proof");

- subtraction or shortening ('scope, for example);

- invention, the creation of a new word (quark, quasar);

- conversion of one word into a different one, though without changing form:

A noun becomes a verb, for example (functional change), or a word takes on a new meaning (semantic change), or a slang word becomes accepted as standard (usage change) -- e.g., TV, countdown, pogo.

Native speakers of English are intuitively familiar with these processes and can use them to create words without conscious thought. And because it is so easy, that's exactly what we do. Create words without any conscious thought.

One of the most frequent patterns we use is the conversion of verbs to nouns by the addition of suffixes: We can take a perfectly good active verb like "classify," for example, and add a noun-making ending to it to form "classification." Then, instead of saying "We classified $X$ into ....," we can write "The classification of $X$ was achieved" (or accomplished or attained or obtained or...). The result is that the healthy verb is smothered and life leaves the sentence.

Now why would anyone want to write that way? I suggested several occasionally valid reasons in the beginning of this discussion, but most of the time the reason is a pure case of self-consciousness and insecurity. It grabs us instantly when we pick up a pencil and realize that we are writing for posterity. We can clearly see some reader, present or future, saying derisively "You classified $X$ ? Nonsense It classifies itself." Or another saying "What's important here -- you or the classification?"

That insecurity must be banished by a deliberate act of will repeated time after time until old habits are changed and self-confidence replaces self-consciousness. There is no derisive reader. There are only interested readers who want information presented clearly and concisely. Remind yourself that a basic characteristic of technical writing is that it is nearly always written in response to a specific request, and it is normally read only for the purpose of getting information [2]. Think about the way you pick up a report that you must get some needed data from; don't you simply want the data as quickly and as painlessly as possible?

Let's look at a few examples of smothered verbs to find an easy way to identify them -- and thus, of course, to eliminate them. Here's an assortment: 
The actual transfer function measurements are obtained and interpretations are made.

Selection of the structural excitation stimulus is determined and repeated application to the test structure is accomplished.

System operation is performed in five distinct functional steps.

Initiation of the aircraft canopy jettison and seat-ejection sequence is accomplished by operation of the seat-ejection control handle.

Normal control of seat-back positions is pilot-selected by actuation of a switch on the aircraft control stick grip.

In examining this distressing collection (taken from just two short articles I've recently edited), we can see a couple of distinct patterns. First, we invariably find a verb that has been convcrted to a noun by the addition of a suffix like "-tion" or "-ment." That's the smothered verb [3], To make it work in a sentence, the author has to add another verb, typically "are made" or "is accomplished" or some other weak passive.

So watch out. Sensitize yourself to "is accomplished" and "are obtained" and "will be done." Look out for those verbs disguised as nouns. When you see that you've written this two-part pattern, ask yourself what it is you really wanted to say. Take the wraps off those poor smothered verbs. (Please note: I am not saying that you should never use passive verbs. They can be quite useful, in fact, as de Beaugrande [4] has pointed out when you want to shift rhetorical emphasis.)

\section{The Freight-Train Adjectival Phrase}

That same old paper on the patterns of word formation [1] that I mentioned earlier discusses the creation of new words by the process of compounding; that is, by adding two or more words together to form a new unit. Some of these new formations are used only once in a particular context and promptly forgotten; others, however, turn out to be useful and efficient expressions that take a permanent place in our vocabulary, such as "blow-back" and "paste-up" and "copyfit."

The process of forming these new compounds is, as I have said, intuitive for native speakers of English. The resulting phrase is usually shorter -- and hence more efficient -- than the equivalent mnventional exprcooion. The problem arises when the process is carried to extremes: Engineers have been yelled at all their lives for-being too wordy, and so when they find a technique that cuts out words -- especially such useless little words as prepositions and articles, they tend to make a career out of it. The result often turns out to be a construction in which attributive adjectives are stacked up in front of a noun in such profusion that one finds himself reading a series of perfectly good English words that makes no sense whatsoever. For example, look at this, the title for a published article: "Electronic Instrument Industry Instruction Manual Preparation Procedures Survey."

Now admittedly, if we rephrased that title into normal word order, it would no longer be a title but more nearly an abstract. We could compromise: "Survey of Procedures for Preparing Instruction Manuals in the Electronic-Instrument 
Industry." This version uses five more words and still keeps one compound modifier (electronic-instrument), but it is intelligible at first reading.

A complicating factor in the use of these freight trains, as they have been called, is the widespread uncertainty surrounding the rules for hyphenating compounds. Properly applied, hyphens can great $1 \mathrm{y}$ clarify the string of modifiers by telling the reader which words function together as a unit. In our example, the hyphen in "electronic-instrument industry" says that the first two words act together to modify industry.

In discussing these piled-up modifiers, Henrietta Tichy [5] points out that technical writing al ready contains enough naturally occurring chains so that writers should avoid adding more. She cites as examples "1500-MeV electron synchrotron" and "Van de Graaff accelerator and electrostatic deflection system." In recommending the use of hyphens for clarification, she asks the meaning of these phrases: "sulphur containing additives," "synthetic plant construction," and "productive time estimates."

In a similar vein, Souther and White [6] ask about the meaning of these stacked modifiers: "long-term surveillance test planning" and "heterogeneous graphite moderated natural uranium fueled low-powered critical nuclear reactor." They point out that the writer reads into each stack of words the relationships he already knows, but the poor reader sees them as an almost insoluble puzzle.

In short, don't go overboard in trying-to be concise. Don't leave out all those necessary little function words. Don't build freight trains if you can avoid it. But if you must, then use hyphens to link words explicitly into unit modifiers.

The Indiscriminate Use of Jargon

Another pattern of word formation is the conversion of technical slang or jargon into accepted terms. For example, the word "barn" is the nuclear physicist's unit of measurement of the probability of interaction between neutrons. It is expressed in square centimeters: $10^{-24}$ square centimeter, to be exact. Now an area of one septillionth of a square centimeter $(1 / 1,000,000,000,000,000,000,000,000)$ may not sound very big to us, but to a nuclear physicist who is used to thinking in terms of subatomic distances, it's as big as a barn. So that's what he called it in his shorthand, his shoptalk. Everyone in his business understood it, of course; it was convenient to use, and so eventually the term entered the dictionary.

The process I've described here is begun all the time, but only rarely does it culminate in the establishment of a generally recognized term. What usually happens is that common use of the specialized term remains restricted to the insiders. To outsiders, the term conveys nothing of its intended meaning. A communication problem arises when the insider forgets that he is not talking to or writing for another insider.

Perhaps the most common manifestation of this problem is the widespread use of acronyms and initials. Just think about $\mathrm{rf}, \mathrm{rpm}$, IC, LSI, NASA, and similar terms. Every technical and scientific discipline has its own collection of 
necessity. No biologist is going to talk very long about Escherichia Coli -he's going to abbreviate it E. Coli. And the only way to talk or write to colleagues about gallium-arsenide enhancement mode junction fieldeffect transistors, for example, is to call them GaAs E-JFETs.

The point I am making here is simple: The use of technical slang and jargon is perfectly natural and acceptable as long as it is kept within the inner circle where it is understood. It is quick, efficient, and clear in the proper context. But the indiscriminate use of jargon or its use to impress the neophyte or the outsider should be scrupulously avoided.

If you need to use a specialized term, teach it to your audience and then go ahead and use it. Think about Walter Cronkite and the other announcers during the Apollo missions. They were able to teach millions of laymen to understand EVA, for instance, and LEM and Capcom and other shorthand expressions that were needed for efficient comminication. We can do the saine - if we're careful.

I must add, by way of a postscript, that this discussion deals only with technical jargon, not ordinary jargon. Every writing text inveighs against "Yours of the 4th instant received and contents duly noted" and such deadwood as "in the event that" in place of "if" [7]. But those faults appear in all kinds of writing; the technical jargon $I$ refer to here is the particular bane of our work.

\section{The Habitual Hedge}

Another idiosyncracy of technical style arises because engineers and scientists are taught from day one to be complete and exact in their work. "We can't have bridges falling down or planes crashing because some small detail was overlooked," they're reminded repeatedly. In school they learn to use the precise language of mathematics. They learn to draw with a degree of accuracy that's measured in millimeters. As a result, when they're forced in English classes to study the use of words -- ambiguous, tenuous, charismatic words -- they're lost. Poetry, with its multiple messages, and fiction, with its different levels of meaning, are beyond their grasp: "Why doesn't he just say what he means?" they moan.

They carry this antipathy toward vagueness into their work after they leave school. Here, for example, is the title of a paper published recently by a couple of our scientists [8]: "Effect of Epnxy Monomer Cryctallisation and Cure Condiliuns on Physical Structure, Fracture Topography, and Mechanical Response of Polyamide-cured Bispheno1-A-Diglycidyl Ether Epoxies." Such precision in language is useful in instances like this because the title, along with the abstract, is such a vital element in other research workers' review and analysis of the literature. To tell those readers any less than this would be to risk misleading them.

However, the technically trained worker seems at times to be constitutionally incapable of descending from his lofty plateau of precision. For.him, all his writing must be capable of withstanding the critical scrutiny of his peers. No matter that what he is writing will be read only by his management or by the public at large; it must be exact, taking account of all possible influences. 
The ironic outcome of this approach is not exactness but vagueness. Witness the following passage, taken from a general description of a new airplane seat designed by our company; the audience is the engineering population of the whole company -- no external readers. "The high-acceleration cockpit/seat can be considered a major advance in tactical weapon system capability. Next-generation fighter aircraft of the 1980-1990 time period may increase pilot tolerance to high sustained accelerations by the design concepts developed in this ejection seat."

Editor: "Why 'can be considered'? Isn't it a real advance?"

Engineer: "We11, we think so, but our competitors might not."

Editor: "Why 'may increase pilot tolerance'? Will it or won't it?"

Engineer: "Of course it will if it's used, but I can't guarantee that it will be bought."

This kind of writing might be called "the habitual hedge" [9]. It is intended to protect the writer against all charges of inexactness or lack of foresight and, in fact, as I've suggested, it is merely the extension of sound engineering practice into verbal fields. It is not caused by a spineless refusal to make a positive statement -- no one can be more assertive than a technical man who is sure of $h$ is facts. But it can produce a pretty dense thicket of ideas: "The modal analysis system, as defined above, has been applied, both incrementally and continuously, to various structures and structural components, including but not limited to simple models, wind-tunnel flutter models, and full-scale aircraft."

When a writer finds himself sprinkling qualifying phrases throughout his sentence like fertilizer on his lawn, he should pause and assess $h$ is purpose and his audience. Does he need to protect himself so thoroughly? Will he really mislead anyone if he simplifies things a bit?

\section{WAYS TO AVOID VERBAL POLLUTION}

As we've discussed these various forms of verbal pollution, I've offered a few specific suggestions intended to help you avoid polluting your own writing. To conclude this discussion, here are several more general bits of advice.

\section{Analyze Purpose}

It is axiomatic that technical text is written for a specific purpose and read for a specific purpose. These two purposes are not necessarily the same. For example, a proposal is written to win business; it is read to evaluate potential contractors. The writer needs to keep both purposes in mind as he works, sometimes subordinating one to the other.

An interesting way of analyzing purpose is described in the first-quarter 1978 issue of Technical Communication. Colby and Rice [10] set up a continuum of purposes ranging from simple documentation of facts, as in a lab notebook, to 
a complex communication of the company image, as in an annual report. Parallel with this range of purposes is a range of writing styles running from purely technical to purely nontechnical.

This way of looking at purpose can be an immediate effect on the writer's approach, $h$ is choice of content, and $h$ is use of language. And the net result of adapting one's writing to one's purpose is to reduce verbal pollution.

\section{Analyze Audience}

Colby and Rice also set up a spectrum of audiences to parallel their spectrum of purposes and styles, but a more detailed procedure for analysis of the audience is described by Dwight Stevenson in a paper presented at the 1977 International Technical Communication Conference [11]. He asserts that the conventional company organization chart does not accurately reflect the real communication system within the company nor the personal characteristics of the individual readers. He recommends the construction of an egocentric organization chart which identifies specific individuals and their proximity to the writer (as opposed to their hierarchical relationship to him). With such a chart, the writer can clearly characterize the individual readers and their purposes -- specifically the kind of action or response the writing will produce in each reader. That information in turn permits the writing to be tailored for best results, and tailored writing tends to have a low level of verbal pollution.

\section{Analyze Readability}

The analysis of purpose and audience should take place before the writing begins. Once the writing is completed, the author might well take a few minutes to check its level of readability. George klare, an authority on readability, out lined in a 1977 article [12] some of the things a writer can do to improve the readability of his work. Basing his advice on the results of research, he recommended six kinds of word changes and six kinds of sentence changes. Some of his suggestions are familiar in our business (use short, concrete, familiar words in short sentences) but some of them are less frequently heard -- and even less frequently heeded. His article deserves to be studied with care and then periodically reread as a reminder.

\section{CONCLUSION}

For technically trained people, it seems to me, the causes of verbal pollution lie largely in their backgrounds. Their characteristic approach to problems, when extended into the world of pen and paper, creates unintended confusion. This confusion takes various forms: verbs turned into nouns, freight-train adjectives, alphabet soup, and so on. But the pollution can be recognized and reduced, if not eliminated, by a bit of conscious effort. Here's a little challenge:

As a start, take a polluted paragraph that you have recently read, do your best to simplify and clarify it, and ask a colleague which version creates the best impression of the author. Then, having seen how easy it is to improve 
someone else's writing, do the same for a paragraph you have recently written. This exercise is really quite simple, but its effects could last the rest of your life.

\section{REFERENCES AND NOTES}

[1] F. R. Smith, "Patterns of Word Formation," STWP Review, vol. 8, no. 3, PP. 8-11, July 1961 .

[2] J. A. Walter, "Technical Writing: Species or Genus?" Technical Communication, vol. 24, no. 2, pp. 6-8, second quarter 1977.

[3] See the discussion in C. D. Linton, Effective Revenue Writing 2, U. S. Treasury Department, 1961 , pp. 81-89.

[4] R. A. de Beaugrande, "Communication in Technical Writing," Journal of Technical Writing and Communication, vol. 8, no. 1, pp. 5-15, 1978 .

[5] H. J. Tichy, Effective Writing for Engineers, Managers, Scientists, New York: Wiley, 1966, pp. 199-200.

[6] J. W. Souther and M. L. White, Technical Report Writing. 2nd ed., New York: Wiley, 1977, pp. 78-79.

[7] For example, see Tichy, op. cit., pp. 134-141.

[8] R. E. Morgan and J. E. O'Neal, Journal of Macromolecular Science-Physics, vol. B15, no. 1, pp. 139-169, Winter 1978 .

[9] I am indebted for this phrase to J. M. Palen, Report Writing for Accountants, Englewood Cliffs, NJ: Prentice-Ha11, 1955, pp. 506-507.

[10] J. Colby and J. A. Rice, "The Documentation Pyramid," Technical Communication, vol. 25, no. 1, pp. 4-6, first quarter 1978.

[11] D. W. Stevenson, "The Writer's Audience: An Egocentric View," Proceedings of the 24th International Technical Communication Conference, 1977, pp. 123-130.

[12]. G. R. Klare, "Readable Technical Writing: Some Observations," Technical Communication, vol. 24, pp. 1-5, second quarter 1977. 


\section{DISTRIBUTION :}

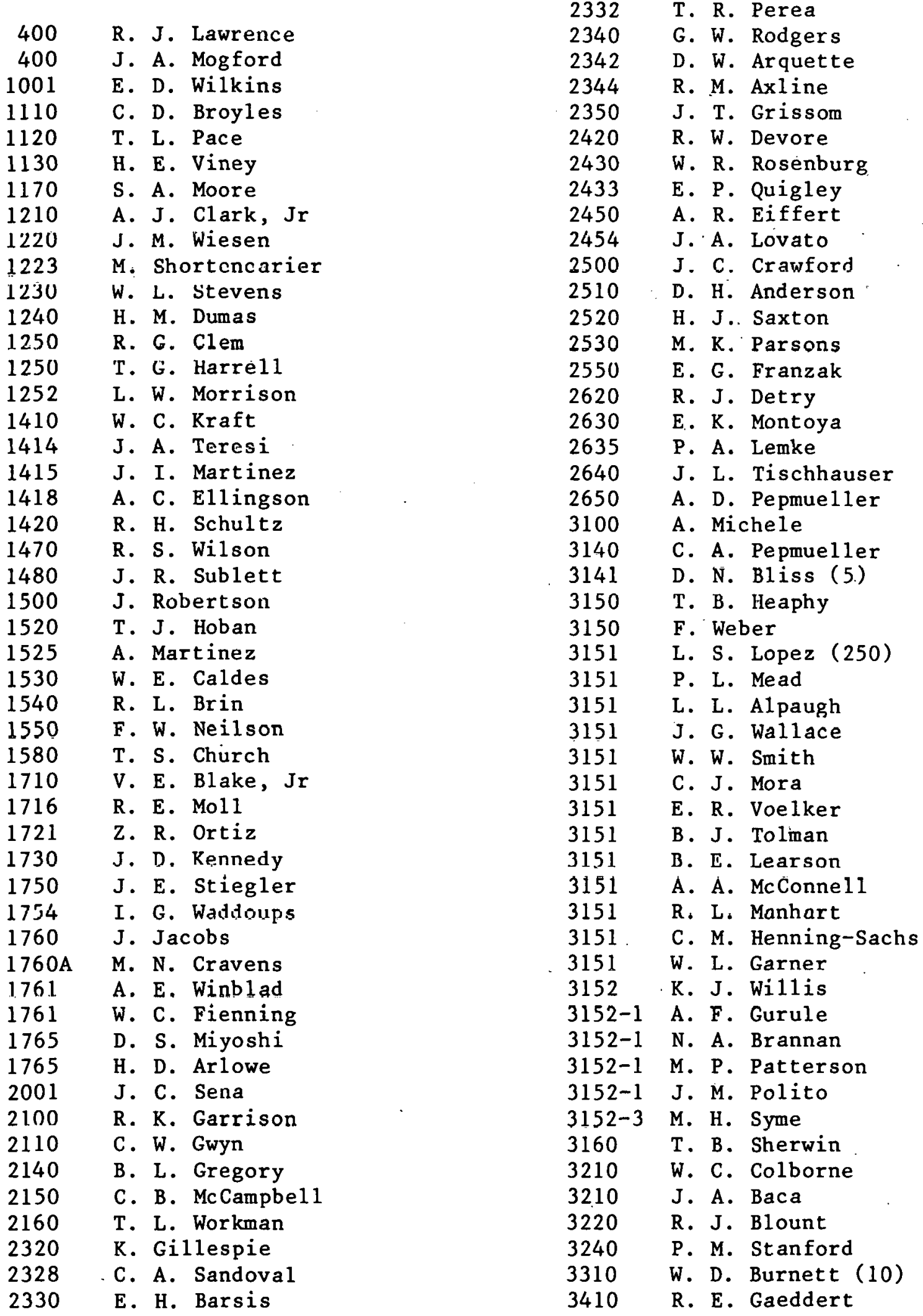




\begin{tabular}{|c|c|c|c|}
\hline 3500 & J. R. Garcia & 4720 & V. L. Dugan \\
\hline 3510 & L. M. Salazar & 4730 & H. M. Stoller \\
\hline 3520 & A. J. Arenholz & 4741 & K. M. Timmerman \\
\hline 3521 & A. L. Hogan & 4744 & L. Bloomberg \\
\hline 3540 & H. G. Pierce & 5001 & S. A. Dean \\
\hline 3610 & L. C. Roper & 5110 & R. L. Schwoebel \\
\hline 3618 & C. Baca & 5130 & G. A. Samara \\
\hline 3640 & H. H. Pastorius & 5150 & J. E. Schirber \\
\hline 3642 & C. M. Morrisett & 5500 & O. E. Jones \\
\hline 3710 & R. W. Foster & 5510 & D. B. Hayes \\
\hline 3720 & L. E. Fuller & 5520 & T. B. Lane \\
\hline 3730 & W. B. Ferguson & 5530 & W. Herrmann \\
\hline 3740 & W. L. Martin & 5610 & A. A. Lieber \\
\hline 3743 & P. Padilla & 5620 & M. M. Newsom \\
\hline 4001 & T. F. Foster & 5630 & R. C. Maydew \\
\hline 4004 & M. J. Beckte11 & 5630 & T. Blair \\
\hline 4210 & J. B. Gerardo & 5640 & G. J. Simmons \\
\hline 4210 & V. Mc Cullough & 5810 & R. G. Kepler \\
\hline 4220 & M. Cowen & 5811 & F. T. Gurule \\
\hline 4240 & G. W. Kuswa & 5820 & R. E. Whan \\
\hline 4250 & T. H. Martin & 5830 & M. J. Davis \\
\hline 4310 & C. C. Burks & 6010 & T. F. Marker \\
\hline 4314 & L. R. Dominquez & 6020 & R. B. Yoder \\
\hline 4320 & G. J. Hildebrandt & 8110 & J. F, Barham, Jr \\
\hline 4330 & E. E. Ives & 8120 & W. E. Alzheimer \\
\hline 4340 & H. W. Schmitt & 8150 & J. L. Wirth \\
\hline 4342 & J. Casey & 8160 & R. D. Cozine \\
\hline 4342 & J. H. Lloyd & 8215 & F. J. Cupps \\
\hline 4343 & E. L. Smith & 8250 & L. E. Davies \\
\hline 4360 & J. A. Hood & 8260 & M. L. Glaze \\
\hline 4400 & J. Christy & 8266 & E. A. Aas \\
\hline 4410 & D. J. McCloskey & 8270 & W. A. Little \\
\hline 4410 & D. Montoya & 8310 & D. A. Schuster \\
\hline 4413 & P. Parra & 8320 & T. S. Gold \\
\hline 1,113 & N. R. nrti.z. & 8330 & G. W. Anderson \\
\hline 4414 & P. R. Bennett & 8340 & W. Bauer \\
\hline 4420 & J. V. Walker & 8350 & D. Hartley \\
\hline 4420 & A. B Tramme 11 & 8410 & R. Baroody \\
\hline 4442 & D. Stavros & 8420 & C. S. Selvage \\
\hline 4445 & L. O. Cropp & 8440 & D. E. Gregson \\
\hline 4445 & B. Stiefeld & 8450 & R. C. Wayne \\
\hline 4450 & J. A. Reusher & 8460 & C. M. Tapp \\
\hline 4510 & W. D. Weart & 3141 & T. L. Werner (5) \\
\hline 4530 & R. W. Lynch & 3151 & W. L. Garner (28) \\
\hline 4530 & D. Hill. & & For DOE/TIC (Unlimited Release) \\
\hline 4533 & S. G. Vandevender & DOE/TIC & $(25)$ \\
\hline 4533 & H. W. Church & & (R. P. Campbel1, 3154-3) \\
\hline 4540 & M. L. Kramm & & \\
\hline 4541 & C. C. Hartwigsen & & \\
\hline 4.550 & R. M. Jefferson & & \\
\hline 4552 & M. Hurley . & & \\
\hline 4552 & A. A. Trujillo & & \\
\hline 4710 & G: E. Brandvold & & \\
\hline
\end{tabular}


